\title{
Comprehensive characterization of sooting butane jet flames, Part 1: soot, soot-precursor, and reaction zone
}

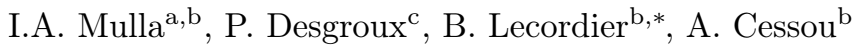 \\ ${ }^{a}$ Department of Aerospace Engineering, Indian Institute of Science, Bangalore, 560012, \\ India. \\ ${ }^{b}$ Normandie Univ., UNIROUEN, INSA Rouen, CNRS, CORIA, 76000 Rouen, France. \\ ${ }^{c}$ Univ. Lille, CNRS, UMR 8522 - PC2A - Physicochimie des Processus de Combustion et \\ de l, Atmosphère, F-59000 Lille, France.
}

\begin{abstract}
The present work examines the effect of Reynolds number $(R e)$ on $n$-butane jet flames, ranging from laminar to turbulent regime $(R e=2100$ to 21500). $n$-butane is chosen since it can represent the oxidation of larger paraffins contained in practical fuels. Several quantities are measured, and various data analysis approaches are employed. Soot volume fraction $\left(f_{v}\right)$ was measured using a laser-induced incandescence technique, whereas polycyclic aromatic hydrocarbons $(\mathrm{PAH})$ and reaction zone $(\mathrm{OH})$ were imaged using laser-induced fluorescence (LIF) tool. The mean and instantaneous images of $\mathrm{OH}, \mathrm{PAH}$, and soot volume fraction are examined. The reaction zone is the least affected by the turbulence, while the PAH-LIF signal is moderately affected. A strong effect of turbulence is observed on the soot concentration and intermittency. Soot and $\mathrm{PAH}$ concentration decreased with $R e$ due to reduced residence time, increased strain rate, and likely increase in a scalar dissipation rate. In the turbulent regime, $f_{v}$ decreases with $\mathrm{PAH}$ at a sharper rate, possibly due to reduced local time scales associated with turbulent eddies. Soot structure complexity is quantified through a fractal dimension $\left(D_{f}\right) . D_{f}$ increased with $R e$; however, in a turbulent regime $D_{f}$ becomes insensitive to $R e$. A semi-global correlation between $f_{v}$ and sheet thickness is also analyzed. A power-law trend is noted in the
\end{abstract}

\footnotetext{
*Corresponding author:

Email address: bertrand.lecordier@coria.fr (B. Lecordier)
}

Preprint submitted to Combustion and Flame

June 30, 2021 
$f_{v}$ vs. thickness plot. Coefficients of power-fit are found to be Re-dependent. Additionally, the local correlation between $f_{v}$ and sheet thickness is examined, which revealed a non-monotonic trend. $f_{v}$ peaks at a preferred soot sheet thickness. These analysis-derived insights can contribute towards the understanding of soot-turbulence interaction. Furthermore, the reported database will facilitate the validation of soot chemistry models intended for practical fuels.

Keywords: jet flames, turbulent sooting flames, soot, butane, PAH

\section{Introduction}

Combustion-generated soot emission adversely affects our health and the environment. Therefore, a fundamental understanding of soot formation is essential to control soot emission. However, soot formation is a complex process that

5 depends on the fuel type, air/fuel mixing, flow field, temperature, and residence time. The influence of such parameters has been elucidated to some extent, both experimentally and numerically. For numerical studies, large-eddy simulations (LES) along with sub-grid models are usually used to predict soot concentration. In LES, two interlinked phenomena, namely turbulence and chemistry, are modeled for sub-grid small scales. For practical devices such as gas turbines or diesel engines, it is necessary to develop computationally feasible and yet reasonably accurate models. Such turbulence-soot chemistry sub-grid models need to be validated against detailed measurements. Therefore, an experimental database with a well-controlled boundary condition is required. Several past works have reported phenomenon-focused soot investigations, while a few aimed at generating the database suitable for validating models of practical interest. Both of such past works are summarized next.

Since combustion in many practical devices is accompanied by turbulence, soot investigations in turbulent flames are desired. Most of the experimental studies in turbulent sooting flames have been carried out in a jet flame configuration. For instance, Lee et al. [1] investigated the relation between soot, polycyclic aromatic hydrocarbons $(\mathrm{PAH})$, and $\mathrm{OH}$ distributions, along with var- 
ious analyses. Qamar et al. [2] reported the soot volume fraction in a turbulent non-premixed jet flame with natural gas fuel. Shaddix et al. [3] reported measurements and numerical modeling results in turbulent non-premixed jet flames with ethylene and kerosene-based JP-8 fuels. The data [3] included soot volume fraction, $\mathrm{OH}$, and $\mathrm{PAH}$ fields. This database has been used recently to validate LES results in [4]. To meet the particular needs of modelers, Köhler et al. [5] devised a flame configuration. A lifted ethylene jet flame without any pilot flame anchoring was chosen. The DLR database $[5,6]$ containing various parameters was used to assess simulations [6]. Gu et al. [7] reproduced the soot concentration measurement in the DLR flame [5] with an excellent agreement. The authors [7] report simultaneous measurements of temperature, soot volume fraction, and soot size. The authors examined correlations between these 35 quantities. Similar multi-scalar measurements in turbulent toluene flame are reported recently by Kruse et al. [8]. The authors [8] showed that soot may not always completely oxidize across the OH-layer.

Apart from the database-oriented studies, parameters influencing soot in turbulent flames are also investigated by a few research groups. The correlation between gas temperature and soot concentration has been examined in laminar [9] and turbulent flames [10-12]. Soot concentration was noted to peak within a preferential temperature range. Park et al. [12] performed simultaneous measurements of the soot and mixture fraction in the soot-inception region. They [12] concluded that soot preferentially forms in a region of low scalar dissipation ${ }_{45}$ rate. Narayanaswamy and Clemens [13] have investigated the effect of strain rate on soot formation. Soot was found to exist at a preferred velocity and local strain rate, independent of the jet exit velocity. Mahmoud et al. [14, 15] reported soot volume fraction trends in turbulent jet flames as a function of exit strain rate at a constant Reynolds number $(R e)$. The total soot yield was observed to vary linearly with the nozzle diameter and fuel flow rate. In recent work [16], a global relationship (power-law trend) between soot sheet width (i.e., thickness) and soot concentration is reported. Time-resolved spatial correlations between the soot, $\mathrm{PAH}$, and $\mathrm{OH}$ distributions were examined by Franzelli et al. 
[17]. Although these simultaneous measurements were qualitative, it provided

55 zone. Soot concentration and particle size in buoyancy-dominated jet flames have been measured by Crosland et al. [18]. Besides the jet configuration, the soot formation has also been investigated in a more complex swirl stabilized flames [19-23].

60 flame lift-off leads to leakage of oxidizer in a fuel zone, which consequently leads to partial premixing. The effect of such premixing has been investigated in detail by Grader et al. [24] in a recent LES study. The authors quantified the extent of premixed and non-premixed combustion regimes through a flame-index 65 [25] approach. It was suggested that the upstream (near flame base) partial premixing could influence soot evolution. Soot formation and growth processes were observed to occur dominantly in the premixed regime, while soot oxidation was postulated to occur mainly in the non-premixed combustion regime.

The effect of $R e$ on soot volume fraction $\left(f_{v}\right)$ has been investigated by a few dent parameters that govern the soot formation are - the mixing field (mixture fraction and scalar dissipation rate), temperature, and residence time. Several soot-influencing quantities change simultaneously with the variation of jet velocity (to alter $R e$ ). The key variables are strain rate, residence time, level of 75 premixing (or mixture fraction) owing to the flame lift-off and turbulent mixing, and scalar dissipation rate which is a function of mixture fraction gradient. The increase in $R e$ (through velocity) is generally accompanied by a decrease in the residence time and an increase in the strain rate. The level of premixing and scalar dissipation rate are expected to increase with $R e$. Therefore, the so observed change in $f_{v}$ with $R e$ is a manifestation of the combined influence of several parameters. Note, though these parameters are interdependent, they may not be used interchangeably while examining their impact on soot. The relative dominance of these soot-influencing parameters is complex to assess, especially in a turbulent flame. 
As noted from the above overview, a wide body of literature exists in sooting flames. The international sooting flame workshop [27] has consolidated data from various groups (Sandia, DLR, Adelaide, TUDelft) to facilitate database access to the modeling community. In most of the works reported so far, ethylene $[1,3,5,7,10]$ or ethylene-based mixtures $[13-16,28]$ were used as a fuel. The so choice of ethylene has been primarily motivated by the considerable soot yield, which enables accurate measurements. Additionally, chemical kinetic mechanisms for ethylene are well-established [14]. A few studies used methane [17] or methane-based mixtures $[2,18]$.

The combustion study of larger alkanes is also necessary since they are im95 portant constituents of practical fuels. Therefore, $n$-butane has been used as a surrogate fuel in spark-ignition engines since it is the smallest paraffin that mimics oxidation of larger paraffins contained in a gasoline [29]. $n$-butane is complex enough to mimic the practical fuels while offering simplicity to facilitate the development of chemical kinetics mechanisms. Thermochemical and combustion properties of $n$-butane are similar to the fuels of practical interest $[30,31]$. Yet, there is no detailed database of turbulent butane jet flames in the literature. Such a database is needed to validate the simulations developed to predict soot formation with fuels of practical interest. The present contribution fills this database gap by providing information on soot volume fraction, soot particle size, soot-precursor (PAH), reaction zone (based on $\mathrm{OH}$ distribution), temperature (in a low-sooting region), velocity field and fuel concentration (in a non-reacting lifted part), and burner wall temperature. To summarize the findings effectively, the paper is divided into two parts. The present article (Part 1) discusses soot, soot-precursor, and reaction zone characteristics. The companion paper (Part 2) [32] focuses on the soot-temperature correlation and soot particle size.

The objectives of the present paper are to report the soot volume fraction in $n$-butane flames and assess the effect of turbulence on soot characteristics. An additional objective is to investigate the correlation between soot concentration, soot-precursor $(\mathrm{PAH})$, and reaction zone $(\mathrm{OH})$. Further contributions include 
fractal and thickness analyses of soot sheets.

\section{Experimental methods}

\subsection{Burner and flame conditions}

The jet configuration was chosen since it provides an axisymmetric flame

120

Figure 1 shows the schematic of the burner along with the overall dimensions. The fuel ( $n$-butane) was injected through a tube of $2.4 \mathrm{~mm}$ inner diameter and $3.1 \mathrm{~mm}$ outer diameter. The fuel tube was surrounded by the co-flowing air, which was issued through a square duct of $400 \mathrm{~mm}$ width. The upstream part mity. The flame was confined up to $750 \mathrm{~mm}$ height above the burner (HAB). The quartz windows provide optical access for laser diagnostics. The optically accessible regions are shaded in Fig. 1 along with dimensions. Although the confinement limits the optical access, it is necessary to avoid flame perturbations caused by ambient currents. The confinement also ensures well-defined boundary conditions. A square exhaust hood of $750 \mathrm{~mm}$ size extracts the combustion gases. The flame perturbation due to entrainment of ambient air from the co-flow exit plane (at $\mathrm{HAB}=750 \mathrm{~mm}$ ) was mitigated by a square annular shield of airflow.

135

The air and fuel flow rates were regulated with thermal mass flow controllers (Bronkhorst) that were calibrated using a Coriolis calibration bench. Based on this calibration, the uncertainty in flow rates is estimated to be within $\pm 1 \%$. Four $n$-butane jet flames were established by varying the fuel flow rate. The mass flow rate of co-flow air was kept constant and high enough $(5 \mathrm{~g} / \mathrm{s})$ to achieve over-ventilated flames. The corresponding bulk velocity of air co-flow is $26 \mathrm{~cm} / \mathrm{s}$. These flame conditions are listed under Table 1 along with Re, lift-off height $\left(h_{\text {lift }}\right)$, flame length $\left(L_{f}\right)$, mean flame width $\left(W_{f}\right)$, bulk velocity $\left(U_{j}\right)$, and exit strain rate $\left(U_{j} / d\right)$. Flame length determined from the photographs is likely to have higher uncertainty in turbulent or unsteady flames. Thus, $L_{f}$ in 
this work is deduced from the $\mathrm{OH}$ presence probability map. Such a map is obtained based on a certain presence threshold applied to the imaged $\mathrm{OH}$ signal (detailed subsequently in Sec. 3.6). $L_{f}$ is obtained by defining the flame-tip at $10 \% \mathrm{OH}$ probability. This criterion marks the external edge of the flame-brush. For $R e=21500$, flame-tip was beyond the imaged data. Nevertheless, $L_{f}$ is estimated by locating the PAH-tip (which was well-imaged for all $R e$ ) from the PAH probability map. The ratio of the lengths of OH-tip to PAH-tip remained nearly constant (with a value of $1.16 \pm 0.01$ ) for $R e=2100,5000$, and 7200 . Thus, the identical scaling factor (ratio) was used to estimate $L_{f}$ for $R e=21500$ flame. The $\mathrm{OH}$ probability map is also used to deduce the mean flame width ${ }_{155}\left(W_{f}\right)$ by considering the radial location of peak $\mathrm{OH}$ probability. This criterion provides the centerline of the flame brush in the radial direction. The lift-off height $\left(h_{\text {lift }}\right)$ is determined by locating the flame base in instantaneous $\mathrm{OH}$ fields. The mean and standard deviation of $h_{\text {lift }}$ are indicated in Table 1. At $R e=21500$ in turbulent flame, strong fluctuations of the flame base leads to higher $\sigma_{h}$. Since the lift-off height is a sensitive parameter, it can be used for a stringent validation of simulation models.

Figure 2 shows the flame photographs acquired using a digital camera (D70s, Nikon) at three following exposures: 1/20 $s$ to image the blue flame base, 1/500 s to visualize soot inception regions, and $1 / 8000 s$ to qualitatively visualize largescale soot structures, especially in a turbulent case. In the $R e=2100-7200$ range, the flame is entirely contained within the co-flow duct. At $R e=21500$, the flame-tip exceeds the confinement of the duct. Some regions were optically inaccessible, as indicated earlier in Fig. 1. Investigated four flames represent an unsteady laminar case (Fig. 2a), transient flow attached flame (Fig. 2b), and low-turbulence lifted flame (Fig. 2c), and a fully turbulent lifted flame (Fig. $2 \mathrm{~d}$ ). The laminar, transient, and fully-turbulent terminologies are based on the exit $R e$ for round jets. These four cases provide modelers an opportunity to validate simulations at different flow regimes. 


\subsection{Boundary conditions} wall temperature for all the flames, and velocity and mixing fields upstream of Re 21500 flame. For brevity, the velocity and mixing boundary conditions are provided in the Supplement (Sections S1.2 and S1.3). An appreciable partial premixing is noted at the base of Re 21500 flame.

Confined sooting flames could alter the duct wall temperature $\left(T_{w}\right)$ through radiative heating. Therefore, $T_{w}$ was measured using thermocouples (Type-K \#397-1488, RS Components). Thermocouples were flush-mounted on the wall at nine axial locations. For thermocouple mounting, quartz-window space was replaced by steel plates. The data was acquired over 10 minutes at a $2 \mathrm{~Hz}$ rate. The mean temperature was obtained by time-averaging the values. To reduce the transient heating bias, measurements were acquired 45 minutes after the flame ignition. An approximately similar approach was adopted for other laser-based measurements. Figure 3 shows the mean wall temperature $\left(T_{w}\right)$ for flames at different $R e$. The wall temperature differs from ambient conditions by as much as $140 \mathrm{~K}$ for the highest $R e . T_{w}$ increases with $R e$ due to increased total soot yield, flue gas volume, and flame vicinity to the wall. The maximum $T_{w}$ is observed for turbulent flame (Re 21500). For laminar flame (Re 2100), the wall does not heat up significantly due to the slender flame. For Re 5000 and 7200 flames, $T_{w}$ remains appreciable even near the exit plane of the co-flow duct.

Temperature profiles follow the axial $f_{v}$ trends until peak- $f_{v}$ location. Beyond this height, convective heating is likely to be dominant due to increased flame vicinity to the wall. A slope discontinuity in the $T_{w}$ profile appears after every three data points. Note, a gasket was used between the thermocouple200 mounted steel plate and the co-flow duct wall. This gasket acts as a conduction insulator. Since three thermocouples were mounted on each plate, the corresponding slope discontinuity is observed across different plates (or thermocouple sets). 


\subsection{Laser diagnostics}

\subsubsection{Laser-induced incandescence (LII)}

In the LII technique, soot particles are heated well beyond flame temperature. The resulting broadband incandescence signal is acquired at a certain wavelength. Once calibrated, the LII signal provides the soot volume fraction. To heat soot particles, infrared wavelength $(1064 \mathrm{~nm})$ of the Nd:YAG laser signal [33-35]. The laser was operated at a $10 \mathrm{~Hz}$ repetition rate. The laser beam was formed into a sheet to obtain the planar LII signal. The light-sheet (LS) was obtained by using a set of cylindrical $(f=-33 \mathrm{~mm})$ and a spherical $(f=1000 \mathrm{~mm})$ lenses. The LS measured $90 \mathrm{~mm}$ in height $\times 0.3 \mathrm{~mm}$ in thick$0.4 \mathrm{~J} / \mathrm{cm}^{2}$. The LS thickness and profile were determined using a beam profiler (WinCam, DataRay Inc.). The LS intensity was found to be uniform within $70 \%$ of the peak. This extent of non-uniformity is acceptable if the LII is performed in a plateau regime (of LII signal vs. laser fluence plot). To verify the plateau, the fluence curve was deduced by measuring the LII signal as a function of laser fluence. Laser energy was controlled using a variable attenuator (containing polarizer and half-wave plate), which facilitated energy variation at a constant laser pulse width $(\sim 7 n s)$. The derived fluence curve is provided in Fig. S7a of the Supplement. Typically, the plateau regime commences around light-sheet remains within a plateau regime with a range of 0.35 to $0.45 \mathrm{~J} / \mathrm{cm}^{2}$. At this fluence, the signal-to-noise ratio (SNR) of the instantaneous LII signal is nominally around 12 , while the $f_{v}$ detection limit is approximately $0.015 \mathrm{ppm}$.

The LII signal was collected normal to the light-sheet using an intensified CCD (ICCD) camera (PI-MAX: 512, Princeton Instruments). The camera was equipped with an imaging lens (105mm $\mathrm{f} / 4.5$, UV-Nikkor) that provided the magnification of 5.75 pixels $/ \mathrm{mm}$ and corresponding square field-of-view (FOV) of $89 \mathrm{~mm}$ in width. The signal was collected through a $400 \mathrm{~nm}$ filter with 
FWHM of $25 \mathrm{~nm}$ (\#86664, Edmund Optics). The blue spectral region (400 nm) mitigates the background noise from soot radiation (at flame temperature). A short prompt gate is needed to avoid signal biases towards larger soot particles that cool down at a slower rate. Thus, the prompt gating was used with a short gate width of $50 \mathrm{~ns}$. The data was acquired at a $10 \mathrm{~Hz}$ rate. The number of acquired images were 1000 for $y<150 \mathrm{~mm}$, and 2000 for higher height $(y>$ $150 \mathrm{~mm}$ ) to ensure statistical convergence. The LII signal was calibrated using the laser-extinction method at $1064 \mathrm{~nm}$. Details of the calibration set-up and data reduction are provided in Sec. S3.1 of the Supplement. Uncertainty sources with respective estimates are detailed in Sec. S3.2. The overall uncertainty in the mean $f_{v}$ is estimated to be $\pm 19 \%$. SNR and detection limit measures about 8 and 1500 counts, respectively. A linear dependence of the OH-PLIF signal with laser energy was verified, and 
the resulting $\mathrm{OH}$ fluence curve is provided in Fig. S8 in the Supplement. The PLIF signal is corrected for light-sheet nonuniformity. For this correction, the light-sheet profile was deduced by assuming a constant $\mathrm{OH}$ intensity along the length of a laminar diffusion flame. Note, the OH-PLIF signal is not intended to be quantitative; instead, it is used to identify the reaction zone location and topology.

An emICCD camera (PI-MAX4: 512 EMB, Princeton Instruments) equipped with a UV lens (105mm f/4.5, UV-Nikkor) was used to image the LIF signal. The camera acquired an image of an $89 \mathrm{~mm}$ square region with a magnification of 5.75 pixels $/ \mathrm{mm}$. A narrowband $310 \mathrm{~nm}$ (\#10BPF10-310, Newport) filter was used, which largely mitigated the interference from PAH-LIF. The camera was gated to $30 \mathrm{~ns}$ relative to the laser pulse. The OH-PLIF images were acquired at a $10 \mathrm{~Hz}$ rate. The numbers of acquired frames were 1500 for $y<150 \mathrm{~mm}$ and 2000 for higher heights $(y>150 \mathrm{~mm})$.

\subsubsection{PAH-PLIF}

PAH, as a soot-precursor, plays a crucial role in soot formation. Thus, the relative concentration and distribution of PAH are examined by acquiring the PAH-PLIF signal. To excite PAH, the same laser excitation system and wavelength $(283 \mathrm{~nm})$ as of $\mathrm{OH}$ was used. However, to avoid PAH-LIF saturation, the pulse energy was reduced to $2.5 \mathrm{~mJ}$. The corresponding fluence was estimated to be $0.02 \mathrm{~J} / \mathrm{cm}^{2}$ for LS of $90 \mathrm{~mm} \times 0.15 \mathrm{~mm}$ dimensions. Such a low fluence is necessary to reduce soot interference from LII. Similar fluence level $\left(0.02 \mathrm{~J} / \mathrm{cm}^{2}\right)$ was used by Olofsson et al. [38] and Köhler et al. [39] to avoid LII interference. The PAH fluorescence was imaged on an ICCD camera (PI-MAX: 512, Princeton Instruments) through a UV lens (105mm f/4.5, UV-Nikkor) that led to the magnification of 5.75 pixels $/ \mathrm{mm}$ (with $89 \mathrm{~mm}$ FOV). A broadband filter of $377 \mathrm{~nm}$ wavelength with the FWHM bandwidth of $50 \mathrm{~nm}$ (\#84109, Edmund Optics) was used, similar to [17]. The LIF imaging camera was gated to $50 \mathrm{~ns}$ relative to the laser pulse. The $283 \mathrm{~nm}$ excitation and $350-400 \mathrm{~nm}$ collection leads to the imaging of LIF signal primarily from two- to four-ring 
PAH (including naphthalene), as interpreted from Refs. [35, 40]. The SNR of the PAH-LIF signal is typically around 15; however, the signal intensity decreases sharply in the turbulent flame. Consequently, for $\mathrm{Re}=21500$, the SNR decreases to 4 , with a detection limit of $\sim 100$ counts. The PAH-PLIF data was acquired at a $10 \mathrm{~Hz}$ rate. The number of acquired PAH-LIF images were 1000 for $y<150 \mathrm{~mm}$, and 2000 for $y>150 \mathrm{~mm}$.

A mild non-linearity in LIF intensity is noted (see Fig. S9a) with laser energy even at a fluence below $0.02 \mathrm{~J} / \mathrm{cm}^{2}$. A possibility of the ICCD camera saturation was verified (and ruled out) by imaging the signal through a neutral density filter. The non-linearity was indeed found to be associated with the partial saturation of PAH-LIF. The deviation from linearity is approximately $305 \pm 7 \%$. Nevertheless, a non-linear LS correction strategy is adapted, as detailed in Sec. S2.3. Such precautions enable a qualitative deduction of PAH concentration. However, note that besides the targeted species concentration, the LIF signal also depends on the local gas temperature (through Boltzmann fraction) and gas composition (due to LIF quenching). This information is not available in the present flames. Even if the temperature and gas composition are known, there are two additional issues specific to the PAH quantification. Firstly, the overlapping excitation and emission spectra of different classes (rings) of PAH [41] eliminate the possibility of isolated detection of a single class of PAH. Secondly, the spectroscopic parameters for accounting collisional quenching are not yet well established. Despite these issues, PAH-LIF can be assumed to be semiquantitative (on a relative basis) for the following reasons. PAH forms at a specific range of temperature and gas composition (mainly the fuel concentration and its gradient). For a given fuel, across different $R e$, the PAH formation conditions (i.e., local temperature and gas composition) may not vary significantly. Thus, the temperature-quenching dependence of the PAH-LIF signal is assumed to be approximately identical across Re. This assumption enables a relative comparison of the PAH-LIF signal on a semi-quantitative basis. Note, the transported (i.e., not locally formed) PAH may not be subjected to such assumptions. Nevertheless, PAH survives only in a narrow region between fuel 

work.

\section{Results and Discussion}

\subsection{Spatial correlation between $\mathrm{OH}, \mathrm{PAH}$, and Soot}

330

Figure 4 shows the mean images of OH-PLIF, PAH-PLIF, and soot volume fraction at $R e=2100$ unsteady laminar flame. Only a relatively steady region of the flame is presented. The unsteadiness is quantified using OH-LIF in the following manner. The flame radius (radial distance between the jet axis and the location of $\mathrm{OH}$-layer centerline) at each $y$ location is extracted for several realizations (1500 frames). The standard deviation $\left(\sigma_{r}\right)$ of the flame radius is found to be $\approx 0.05 \mathrm{~mm}$ for $y<60 \mathrm{~mm}$, whereas $\sigma_{r}$ increases to $0.7 \mathrm{~mm}$ at $y=120 \mathrm{~mm}$. As these $\sigma_{r}$ values are comparable to the flame thickness, flame until $y=120 \mathrm{~mm}$ is assumed to be a quasi-steady. This assumption permits analysis of spatial correlations between reaction zone (marked by $\mathrm{OH}$ ), soot precursor, and soot.

Apart from the OH-PLIF signal, an internal low-intensity annular structure is observed around the jet core in Fig. 4a. Recall that the $\mathrm{OH}$ excitation and detection wavelengths are $283 \mathrm{~nm}$ and $310 \mathrm{~nm}$, respectively. Thus, a minor LIF contribution from two-ring PAH (i.e., smaller PAH) [35, 40] is expected. For convenience, we assign the term smaller PAH to benzene or two-ring PAH. The $\mathrm{PAH}$ signal in Fig. 4b is entirely contained within the inner edge of $\mathrm{OH}$ isocontour (at 3500 counts). We also note similar observations in a simultaneously acquired $\mathrm{OH} / \mathrm{PAH}-\mathrm{PLIF}$ dataset (not shown) in the same flame. In Fig. 4b, $\mathrm{PAH}$ distribution at the flame base shows an annular structure. PAH inception occurs at $y \approx 8 \mathrm{~mm}$, and it grows rapidly with height. PAH structure in Fig. 4b is located radially outward that of the smaller PAH signal observed in Fig. 4a. The spectral detection window of $350-400 \mathrm{~nm}$ in PAH-LIF (Fig. 4b) favors imaging of two- to four-ring $\mathrm{PAH}[35,40]$ to which we notionally assign the 
term, relatively larger PAH. As expected, larger PAH forms radially outwards dimensional flame structure and not necessarily to the local extinction. The large-scale flame wrinkling is observed well-downstream in a $y=450-600 \mathrm{~mm}$ 
region. Such wrinkling is not present in the laminar flame $(R e=2100$ in Fig. S10). A mild flame wrinkling is noted at transitional Re (5000 - 7200, in Fig. S10).

The OH-layer at the base of the turbulent flame (Fig. 5a) is thicker than lower $R e$ flames. Since the $R e=21500$ flame is considerably lifted, the jet turbulence leads to considerable partial premixing in the upstream region, as evidenced from the measured mixing field (detailed in Sec. S1.3 of the Supplement). The partial premixing can create favorable conditions for the formation of an edge flame containing tribrachial structure [45]. From the measured velocity field (Sec. S1.2), we also note the flow divergence upstream of the flame base. Such flow divergence along with the partial premixing is an indication of 395 the edge flame structure [46]. This structure could broaden the $\mathrm{OH}$ distribution owing to the merger/vicinity of the non-premixed and fuel-lean branches of the triple flame. Additionally, turbulent transport may also play a secondary role in $\mathrm{OH}$ broadening. The partial premixing can influence the soot formation as discussed subsequently in Sec. 3.5.

The mean OH-LIF signal in Fig. 6a decreases significantly with height, while instantaneous OH-LIF showed in Fig. 5a does not show such a substantial diminution. The mean signal is averaged unconditionally. Therefore, any intermittency (instants without $\mathrm{OH}$ presence) will decrease the mean signal. Thus, the unconditional mean in a fluctuating field implicitly represents the intermittency component along with the instantaneous signal intensity. Consequently, for model validation purposes, the unconditional mean can be used to compare the combined effect of intermittency and concentration (signal intensity). Apart from the drop in the intensity, the mean $\mathrm{OH}$ distribution also shows an increase in the flame-brush thickness with height owing to the in${ }_{410}$ creased radial fluctuations. The mean reaction zone is thicker (relative to lower Re cases included in Fig. S11) even at the flame-base. This is primarily due to the broadening of the instantaneous OH-layer owing to the edge flame structure and turbulent transport, as discussed earlier.

Figure 5b shows the instantaneous distribution of PAH. For better visual- 

2000 shots at higher heights. The resulting mean PAH image is shown in Fig. 6b. Since the light-sheet profile correction is one-dimensional (only along the height), a two-dimensional artifact remains. This artifact is attributed to the use of a dichroic mirror in the collection path, which produces a vignetting 420 effect.

The instantaneous PAH structure (Fig. 5b) exhibits a diffused appearance. High-intensity patches of PAH are observed throughout the field. The formation of a key PAH (naphthalene) is known to be highly sensitive to the local scalar dissipation rate [47]. Naphthalene was observed to form preferentially in regions of lower scalar dissipation rate. In the present work, the chosen PAH excitation/detection scheme also captures naphthalene. Thus, the observed intense local patches could be attributed to the spatial fluctuations of the scalar dissipation rate associated with the turbulent mixing process.

At the base of the flame, the mean PAH-LIF intensity (Fig. 6b) increases sharply with height. PAH inception occurs $\sim 30 \mathrm{~mm}$ downstream of the flame lift-off height. The annular PAH structure merges at a downstream distance. Subsequently, the PAH-LIF intensity along the axis remains reasonably constant over a certain distance. The axial PAH intensity peaks at a location where the flame radius (interpreted from Fig. 6a) measures maximum. The PAH signal decreases rapidly near the flame-tip region.

Figure $5 \mathrm{c}$ shows the composite image of instantaneous $f_{v}$. Unlike PAH, the soot structures are highly localized even in a downstream region $(y=450-$ $590 \mathrm{~mm}$ ) of the turbulent flame. This is attributed to a high Schmidt number of soot particles, which leads to a low soot diffusivity [47]. At the downstream 440 region, patches of intense soot are observed with low-intensity soot filaments throughout the field. A similar pattern of high-intensity patches is noted in the instantaneous PAH field (Fig. 5b). Overall, the soot sheet structure appears drastically different from the reaction zone distribution (see Fig. 5a). Since the soot precursor $(\mathrm{PAH})$ concentration is highly sensitive to the scalar dissipation rate, the soot formation is affected mainly by the fuel concentration gradient 
rather than the reaction zone topology.

Figure $6 \mathrm{c}$ shows the mean soot concentration. Soot forms downstream of the PAH region, which is accompanied by a continuous decrease in the PAHLIF signal. This can be clearly observed with lower Re flames (mean PAH distribution in Fig. S14, and $f_{v}$ in Fig. S19). This is consistent with the fact that PAH have been known to contribute to the soot inception and further to soot growth through condensation on soot particles [48]. In Fig. 6c, peak- $f_{v}$ is observed along the flame axis near the flame-tip region. In the peak- $f_{v}$ region, the mean PAH signal (Fig. 6b) is low, as most of the PAH have been involved in soot formation. Relative to instantaneous $f_{v}$, mean values are significantly lower. Note that the soot is highly intermittent in space and time. Consequently, the mean $f_{v}$ is affected by the unconditional averaging in a highly intermittent field. Therefore, we subsequently deduce a conditional average that isolates the intermittency effect.

460

The unconditionally time-averaged peak- $f_{v}$ in the present turbulent butane flame $(R e=21500)$ measures $0.07 \mathrm{ppm}$. To enable the comparison with ethylene (which is most studied) fuel, we also performed LII measurements in a lifted ethylene turbulent flame at a comparable jet-exit velocity $\left(U_{j}=31.3 \mathrm{~m} / \mathrm{s}\right.$, $\left.R e=8700, h_{\text {lift }}=7.5 \mathrm{~mm}\right)$ relative to the butane flame $\left(U_{j}=27.1 \mathrm{~m} / \mathrm{s}\right.$, $465 h_{\text {lift }}=53 \mathrm{~mm}$ ). The velocity for ethylene case was slightly higher to ensure a lifted flame. In this ethylene flame, time-averaged peak- $f_{v}$ is found to be $0.57 \mathrm{ppm}$. Thus, for a lifted turbulent flame at a given jet velocity, butane appears to produce about $1 / 8$ times the $f_{v}$ found in ethylene fueled flames, on a time-averaged basis. Note that besides fuel type and velocity, the difference in $h_{\text {lift }}$ may influence soot concentration owing to oxidizer leakage in a fuel stream. Therefore, we compare the peak- $f_{v}$ of the present ethylene flame with that of a lifted DLR ethylene flame $\left(U_{j}=44 \mathrm{~m} / \mathrm{s}, R e=10000, h_{\text {lift }}=26\right.$ $m m$ ) [5]. Despite the difference in lift-off heights of DLR and present ethylene flame, peak- $f_{v}$ is found to be nearly identical, i.e., 0.54 ppm in the DLR flame 475 and $0.57 \mathrm{ppm}$ in the present flame. The extent of upstream partial premixing owing to different $h_{\text {lift }}$ does not appear to be prevalent at a peak- $f_{v}$ region. 
A possible reason for this behavior can be found in a LES study by Grader et al. [24]. The authors showed that mainly the soot formation and growth are affected by upstream partial premixing, while in the downstream regions, the 480 soot oxidation is dominated by the non-premixed combustion regime.

\subsection{Soot intermittency and conditional mean}

To characterize soot intermittency, we deduce the soot presence probability similar to the past works $[1-3,11]$. Soot probability is defined as 1 when the $f_{v}$ is above a certain threshold and 0 otherwise. Recall, the detection limit of the LII signal is around $0.015 \mathrm{ppm}$. Nevertheless, similar to [3], a threshold of $0.03 \mathrm{ppm}$ is chosen to discard any spurious noise safely. Each instant provides a binary map of the soot presence. A number of such instantaneous maps are averaged, and the resulting mean probability is shown in Fig. 7a for Re 21500 (maps for other Re are available in Sec. S9). Lower probability values in Fig.

$4907 \mathrm{a}$ explains an order of magnitude difference between the time-averaged (Fig. 6c) and instantaneous (Fig. 5c) soot concentrations.

To isolate the intermittency effect on the mean, we deduce a conditional average by considering samples only with the soot presence $\left(f_{v}>0.03 \mathrm{ppm}\right)$. At least 200 conditional samples at a given location are ensured for averaging.

495 The conditional mean $f_{v}$ field is shown in Fig. 7b. Similar data for other Re is available in the Supplement (Sec. S10). In the inception regions, Soot is highly intermittent (low probability). This is likely due to higher scalar dissipation and strain rates near the jet-exit regions. Soot probability increases with height. The scalar dissipation rate in the downstream region is expected to be lower, owing to reduced flow velocity. Additionally, the soot concentration increases with downstream distance owing to the increased residence time. These two factors can increase soot probability in downstream regions.

Since the intermittency is isolated, the conditional mean $f_{v}$ is higher than the unconditional one. There are two main differences relative to the unconditional mean: 1) The annular soot-containing region extends to a higher HAB than observed in the unconditional mean. 2) The axial/centerline peak- $f_{v}$ is located 
further downstream than that of the unconditional mean. A similar observation has been reported in [18]. Results in Fig. 7 imply that near the flame-tip region, instantaneous $f_{v}$ is appreciable, but soot is more intermittent owing to oxidation. Soot concentration in the present butane flame is compared with the ethylene flame as before, but on the conditional mean basis. The conditionally averaged peak- $f_{v}$ in the turbulent butane flame (at $U_{j}=27.1 \mathrm{~m} / \mathrm{s}, R e=21500$ ) is $0.3 \mathrm{ppm}$, while in ethylene flame (at $U_{j}=31.3 \mathrm{~m} / \mathrm{s}, R e=8700$ ) it is $0.6 \mathrm{ppm}$. By accounting for soot intermittency, butane fuel produces $1 / 2$ times $f_{v}$ found in the ethylene flame. Recall, this factor is $1 / 8$ if the soot intermittency is unaccounted for.

\subsection{Soot-PAH correlation}

In the preceding sections, mainly the results of a $R e=21500$ flame are discussed. For brevity, data for other flames are included in the supplement. This data is used to examine the effect of $R e$ variation on $f_{v}$. A peak- $f_{v}$ parameter is used as a representative value due to its low sensitivity to the lift-off originated partial premixing, as explained subsequently. Recall, from Table 1, Re 2100 and 5000 flames are attached, while at higher Re, the flames are lifted. The conditionally averaged data is considered to avoid intermittency biases. The extracted axial (i.e., along the jet centerline) and global peak- $f_{v}$ values are plotted in Fig. 8a as a function of Re. A piecewise polynomial is fitted to guide the eye. The global and axial peak- $f_{v}$ values exhibit an identical trend with $R e$. The global peak- $f_{v}$ can occur off-axis, either near the flame-tip or in the annular structure.

As $R e$ increases, $f_{v}$ decreases with a weakly exponential or possibly linear trend in the $R e=5000-21500$ range. This $f_{v}$ decrease with $R e$ is primarily attributed to the increased scalar dissipation and flow strain rates. The discussion on this aspect is extended subsequently in Sec. 3.5, where the analysis is based on the instantaneous $f_{v}$ data. In the inception region, besides the flow strain, partial premixing also influences the soot formation. Due to differences in flame lift-off characteristics, the upstream local premixing levels inevitably 
vary with $R e$. Note, the downstream peak- $f_{v}$ region signifies the transition of soot growth and oxidation zones of the jet flame. As stated earlier (in Sec. 1), based on [24], the soot oxidation region of the flame is likely to be dominated ${ }_{540}$ by the non-premixed mode of combustion. Thus, the peak- $f_{v}$ value is expected to have a weaker sensitivity to upstream partial premixing.

The conditional mean maps are also deduced for PAH-PLIF (available in Sec. S6). The PAH presence threshold is set to 150 counts, while the detection limit is 100 counts. A higher threshold is used to avoid a possible influence of noise. The axial and global peak PAH-LIF intensity values are extracted from the conditional mean. The axial and global peak intensities in Fig. 8b are almost identical, except for the laminar flame $(R e=2100)$. Recall that some of the regions are optically inaccessible. Thus, the actual axial peak may not have been well-captured. This issue of optical inaccessibility is of lesser concern in other flames due to larger flame length and axially uniform PAH-LIF intensity over a considerable distance. Therefore, only the global peak PAH trend is discussed. Note, with the missing field, it is not possible to conclude whether the axial and global peaks could differ in $R e=2100$ flame.

PAH-LIF intensity variation with $R e$ is shown in Fig. 8b on the linear scale. ${ }_{555}$ We also examined Fig. 8b on the log scale (not shown) to facilitate comparison with the DNS results reported in Refs. [47, 49], where the authors examined the sensitivity of naphthalene mass fraction to local scalar dissipation rate (which is expected to increase with $R e$ ). Overall, the trend is in qualitative agreement with the DNS results. This apparent consistency implies that the PAH-LIF intensity trend could represent the PAH concentration behavior.

As $R e$ increases, the PAH-LIF intensity drops sharply until $R e=7200$, as noted from Fig. 8b. In the $R e=7200-21500$ range, the PAH-LIF signal drops asymptotically at a lower rate. Although both the soot and PAH intensity drops with increasing $R e$, the rate of decrease of soot with PAH is different for laminar and turbulent regimes. This is better visualized in Fig. 8c, where the conditional peak- $f_{v}$ is plotted against the peak PAH-LIF signal for respective $R e$. Both the axial and global peak-based data show similar trends. In 
the $R e=2100-7200$ range, the rate of change in soot concentration with the $\mathrm{PAH}$ signal is constant. In the turbulent regime $(R e=7200-21500)$, a strong correlation between soot concentration and PAH intensity is observed. Besides $\mathrm{PAH}$, soot in turbulent flames can be affected by an increased flow strain and reduced residence time. A wide range of flow scales (large characteristic scale to Kolmogorov scale) exists in turbulent flows owing to eddies. Since soot formation timescales are relatively longer $(>m s)$ than that of PAH, shorter local

575 residence timescales (due to small-scale eddies and turbulent fluctuations) in a turbulent flow may reduce the soot concentration, possibly by limiting the involvement of PAH to soot formation. To verify this, we estimate a spatial rate of PAH consumption by comparing the conditional mean PAH-LIF intensity at axial peak- $f_{v}$ (centerline) location with that of a respective peak-PAH intensity along the flame axis. From this analysis, the rate of PAH consumption is noted to reduce with an increase of $R e$. As $R e$ increases, global residence time decreases owing to a higher velocity. In a turbulent regime, besides global flow timescale, the local residence time may reduce substantially (compared to soot formation/growth timescales) owing to turbulent eddies. Thus, in turbulent flames, in addition to the PAH concentration, the residence time is likely to be a governing parameter. This is a possible explanation for the observed difference in the soot-PAH correlation between laminar and turbulent regimes.

\subsection{PDF of soot concentration}

The conditional mean revealed the global trends with $R e$. The local instantaneous $f_{v}$ is also important. Since the flame length varies with $R e$, quantities at a fixed axial location are not comparable across different flames. Therefore, we perform the local analysis at an axial location where unconditional mean $f_{v}$ peaks (denoted as $y-p k$ ).

The locally maximum $f_{v}$, within the radial domain of $r=-44$ to $45 \mathrm{~mm}$ and the axial location of $y$-pk $\pm 5 \mathrm{~mm}$, is extracted from each instant, without any threshold condition. Such peak- $f_{v}$ samples over 2000 realizations are used to evaluate the probability density function (PDF). The resulting PDFs are 
shown in Fig. 9, along with the respective analysis region $(y)$ in the inset. $f_{v}$ varies from $0-4 \mathrm{ppm}$ in non-turbulent flames, and from $0-2 \mathrm{ppm}$ in the turbulent flame (Fig. 9d). A peak near 0 ppm indicates either a negligible soot concentration or the absence of soot due to intermittency.

To examine the effect of $R e$ on soot concentration, the most probable (i.e., mode) $f_{v}$ is obtained from PDF as indicated by a red circle. Figure $9 \mathrm{e}$ shows the variation of mode- $f_{v}$ with $R e$, where the error-bar indicate an estimated standard deviation $\left(\sigma_{\text {Gauss }}\right) . \sigma_{\text {Gauss }}$ is obtained by evaluating full width at half maximum (FWHM) of the PDFs. Next, FWHM is related to $\sigma_{\text {Gauss }}$ by invoking the assumption of Gaussian distribution.

In Fig. 9e, as Re varies from 2100 to $5000, f_{v}$ increases, despite the increase in exit strain rate. To examine further, we also evaluate PDFs and mode- $f_{v}$ at a peak- $f_{v}$ location occurring along the axis in the conditional mean $(y-p k C)$ data. These PDFs and related data extraction procedure are provided in the Supplement (Sec. S11). Figure 9f shows mode- $f_{v}$ trend with $R e$ at $y$-pkC location of the respective flame. The increase in $f_{v}$ from $R e=2100$ to 5000 is much milder than that of Fig. 9e. Nonetheless, in this Re range with increasing strain rate, $615 f_{v}$ does not decrease. Note, the $R e=2100$ flame is buoyancy dominated, while the other flames are momentum dominated. This difference can influence the mixing process and residence time relative to the soot formation timescales [26]. This may be the reason for different $f_{v}$ trend between $R e=2100$ to 5000 .

For non-laminar flames $(R e=5000-21500), f_{v}$ drops with $R e$ in both Figs. 9e and 9f. As apparent from Fig. 9e, the $f_{v}$ trend is closer to an exponential fit than a linear fit, though the difference is not significant. To confirm the type of fit function reliably, additional data points are needed. Nonetheless, an exponential trend has been reported with strain rate in laminar one-dimensional flames $[50,51]$. The $f_{v}$ trend in Fig. $9 \mathrm{f}$ resembles as of the conditional mean $f_{v}$ in Fig. 8a. In the $R e=5000-21500$ range, the trend appears to be linear. An identical linear trend of $f_{v}$ with exit strain rate is reported in ethylene-based turbulent jet flames [14]. Despite this agreement, data points at an additional $R e$ are needed to establish the fit function with certainty. 
An early explanation for the decrease in $f_{v}$ with $R e$ was provided by Kent kinetics is faster than the air-fuel mixing (or diffusion) rate, and thus the process is mixing rate controlled. Conversely, at a high flow rate, the mixing rate exceeds the soot formation timescales, and therefore soot chemical kinetics becomes the limiting factor. Consequently, the soot concentration decreases with the increase in strain (or flow) rate. Bisetti et al. [47] provide further insights by demonstrating the high sensitivity of naphthalene (soot-precursor) to the scalar dissipation rate. Naphthalene concentration was shown to decrease in a region with a high dissipation rate. As expected, soot concentration was noted [47] to drop sharply with a reduction in naphthalene concentration. The scalar with an increase in $R e$ (accompanied by a rise in strain and scalar dissipation rates), the soot concentration drops exponentially/linearly in Figs. 9e or 9f. Besides the exit strain rate, local mixture fraction also plays a key role since the soot concentration is governed by fuel pyrolysis reactions, which in turn is a function of the mixing field. In a lifted flame, partial premixing could suppress the soot formation. However, as discussed earlier, at the peak- $f_{v}$ location, the impact of upstream premixing is expected to be low as interpreted from a numerical study [24]. Despite the varying level of upstream premixing (owing to different lift-off characteristics) in the present flames, the peak- $f_{v}$ region is likely to be dominated by the non-premixed combustion regime. Nevertheless, the variation of the local scalar dissipation rate with $R e$ may affect the soot locally. Further measurements and analyses are needed to understand the effect of partial premixing and scalar dissipation rate on $f_{v}$ locally.

\subsection{Intermittency in $\mathrm{OH}, \mathrm{PAH}$, and Soot}

In Sec. 3.3, soot occurrence in a turbulent butane flame is shown to be highly intermittent. This soot intermittency is compared with the intermittency in soot-precursor $(\mathrm{PAH})$ and reaction zone $(\mathrm{OH})$ as a function of Re. An identical approach as of soot probability is used to deduce $\mathrm{PAH}$ and $\mathrm{OH}$ prob- 
ability maps. For $\mathrm{OH}$, the presence threshold is set to 3000 counts, which is higher than the detection limit (1500 counts). This threshold is chosen based on the intensity gradient of the OH-LIF and background signal. The binarized OHlayer is assumed to mark the reaction zone region. The binarization threshold for $\mathrm{OH}$ is kept constant across different flames since the instantaneous OH-LIF signal does not change significantly with Re. In contrast, PAH-LIF signal intensity varies widely with $R e$ and also along the flame height. Thus, a dynamic local threshold approach is used. For a given flame and axial location, the threshold is defined as the $50 \%$ of the radial peak value noted in the conditional mean data at a respective $y$ location. This choice marks the region of PAH prominence. In low signal regions (e.g., in $R e=21500$ flame or near flame-tip), 670 conditional mean based threshold condition may fall below the detection limit ( $\sim 100$ counts). In such a scenario, the minimum threshold of 150 counts is imposed, which is identical to the value used for evaluating the condition mean $\mathrm{PAH}$ field. The resulting PAH probability maps are provided in Supplement (Sec. S7), along with further details of the rationale for threshold parameters.

675 Note, threshold choices will alter the probability values, but the spatial distribution is not expected to differ qualitatively. Once the probability is evaluated, the peak value along the jet axis is used as a representative value. The identical method is used to extract the characteristic probabilities for $\mathrm{OH}$ and soot. This approach accounts for varying flame lengths across different Re. Additionally, for a given flame, the axial locations of peak probability for $\mathrm{OH}, \mathrm{PAH}$, and Soot are allowed to vary (while $r$ is restricted to flame axis/centerline). Thus, differences in the respective species distributions (i.e., overall height) owing to different formation-timescales are accounted for.

Figure 10 shows the variation of mean peak probability of $\mathrm{OH}, \mathrm{PAH}$, and 685 soot with $R e$. For soot, besides a fixed threshold, we also used a dynamic local threshold with identical parameters (detailed in Sec. S9) as of PAH. As observed in Fig. 10, no significant differences in soot probability trends are noted between the dynamic (Soot-D) and fixed (Soot-F) threshold approaches. This is a consequence of the identical order of magnitude of instantaneous $f_{v}$ 
across $R e$ and lower diffusivity soot in space.

The $\mathrm{OH}$ presence probability does not change appreciably with $R e$. This suggests that the effect of turbulence on the reaction zone fluctuation is not significant in the present jet diffusion flames. The soot-precursor shows moderate sensitivity to $R e$. PAH probability increases in the $R e=2100-5000$ range.

695 There is a possibility that the actual axial/centerline peak of PAH probability for $R e=2100$ may not have been imaged, as discussed earlier. Recall that the PAH-LIF intensity in the $R e=2100-5000$ range decreases sharply (Fig. 8b). As discussed earlier, $R e=2100$ flame is buoyancy-dominated, while at higher Re flames are momentum-dominated. This may have an impact on the mixing field and, consequently, on PAH behavior. Coherent PAH structures are noted in instantaneous images at $R e=5000$ (Fig. S13b) due to flow instability associated with transitional $R e$. These structures enhance PAH transport towards the flame axis (centerline), and thus leading to a higher probability. With a further increase in $R e$ from 5000 to 21500, the PAH presence probability appears to decrease linearly. The probability approximately drops from 1 to 0.6 . The intermittent nature of $\mathrm{PAH}$ at higher $R e$ is attributed to fluctuating strain and scalar dissipation rates, which drastically affects PAH formation [47].

The soot presence probability trends follow the identical behavior as of $\mathrm{PAH}$, although with lower probability (i.e., high intermittency). The overall soot probability trend appears quite close to that of the mode- $f_{v}$ shown in Fig. 9f. In the $R e=2100-5000$ range, soot probability increases slightly. Similar to the PAH explanation, this increase in probability is either due to differences in mixing mechanism (buoyancy vs. momentum) or due to unresolved axial peak. For the $R e=5000-21500$ range, the soot probability decreases similar to PAH 715 probability. However, the rate of decrease is sharper than the PAH probability. The increase in $R e$ is likely accompanied by elevated strain and scalar dissipation rates, which result in a lower concentration of the soot-precursor (Fig. 8b) with a reduced probability that consequently is expected to decrease the soot probability. Relative to $\mathrm{PAH}$, soot probability is consistently lower for several reasons. Besides $\mathrm{PAH}$, the soot formation also depends on two other key param- 
eters, namely temperature and residence time. Fluctuations of these quantities in a turbulent flame can increase soot intermittency in both space and time. The chemical timescales of soot formation are longer than that of PAH, which can also contribute to higher intermittency due to lag [52] in response to change in local conditions. Finally, soot is not as diffusive as PAH, and this can lead to lower probability due to high soot intermittency. To summarize, the reaction zone intermittency is least affected by turbulence, while PAH are moderately affected, whereas soot intermittency is greatly influenced.

\subsection{Fractal dimension of soot filaments}

Fractal dimensions can provide a quantitative description of the complexity of the soot sheet/filament field in terms of wrinkling and fragmentation. Such analysis has been applied in the past to investigate turbulent flows [53] and premixed flames $[54,55]$. Fractal dimensions are generally reported for aggregated soot particles, for instance, in Ref. [56]. We apply the fractal method for the first time to analyze soot filament fields (as in Fig. 5c) in turbulent non-premixed flames.

An overview of the fractal theory and background can be found in $[53,54]$. LII data provides a planar slice of the three-dimensional soot structure. Thus, the fractal dimension of only a $2 \mathrm{D}$ field $\left(D_{2}\right)$ is accessible. Nevertheless, the characteristic fractal dimension of a surface $\left(D_{f}\right)$ is approximated as $D_{2}+1$, following [53]. To calculate $D_{2}$, a box-counting method [53] is used. The method involves overlaying the image with a grid of a given size $(\epsilon)$ and counting the number of boxes $\left(N_{b}\right)$ needed to cover a given pattern entirely. The procedure is reiterated with a grid of successively larger box sizes (in a step of $2^{n}$ ). The slope, derived from the log-log plot of $N_{b}$ vs. magnification $(1 / \epsilon)$, provides the fractal dimension.

Before applying the fractal analysis, it is necessary to identify the soot filaments. This is not a trivial task due to the complexity of soot sheets in turbulent flames. A local adaptive threshold approach is employed to binarize the soot 750 sheets. The details of image processing are available in Supplement (Sec. S12.1). 
Once the soot sheets are identified, there are several analysis approaches. $D_{f}$ could either be obtained for soot filament silhouette (blobs), borderline/outline, or skeleton [57]. We found that these three choices only weakly affect the $D_{f}$ trends; however, the absolute values differ. Silhouette- and outline-based $D_{f}$ values are sensitive to threshold choices, whereas skeleton-based $D_{f}$ would be least sensitive. Thus, we use the skeleton of the soot sheets to evaluate the characteristic $D_{f}$. Note, $D_{f}$ can be calculated either for an isolated soot filament or for an imaged sub-field containing several filaments. The former approach can provide the extent of filament roughness (i.e., wrinkling), while the latter will give the combined estimate of both the roughness and fragmentation. Since the soot sheets are not two-dimensional, $D_{f}$ evaluated from isolated soot filaments could be biased. Therefore, we calculate $D_{f}$ for the imaged soot sub-field to obtain both - the extent of wrinkling and fragmentation, similar to [53, 54, 58].

For reference, media files containing 20 sample frames of instantaneous $f_{v}$ sub-fields (at different axial stations) are provided in the Supplementary Material for all the flames. Instantaneous $D_{f}$ is calculated only for images in which soot is present (i.e., $f_{v}>0.03 \mathrm{ppm}$ ). $D_{f}$ values obtained over several frames are used to calculate the mean and standard deviation. The variation of mean $D_{f}$ along the flame height is shown in Fig. 11 for different Re. The axial domain 770 of $D_{f}$ evaluation sub-field is marked by the horizontal bar, whereas the vertical bar indicates the standard deviation of $D_{f}$. The radial domain is kept constant $(r=-44$ to $45 \mathrm{~mm})$ for all the cases. In principle, $D_{f}$ is expected to be greater than 2. Lower $D_{f}$ in Fig. 11 is due to the use of the skeleton of soot filaments. Additionally, the largest object-bounding box size $(\epsilon$ is varied in a step of power of 2) cannot be of the same size as of the object-bounded image size, which results in so-called over-empty boxes [59]. Nonetheless, in the peak- $f_{v}$ region, $D_{f}$ is appreciable greater than 2 .

For a given $R e$, in the soot inception region $D_{f}$ remains low. The peak- $D_{f}$ region nearly coincides with the sub-field where unconditional mean peak- $f_{v}$ is observed. $D_{f}$ decreases in the downstream oxidation region. These observations indicate that the soot sheet wrinkling and fragmentation are highest between 
soot growth and oxidation regions. In the soot inception regions, $D_{f}$ unexpectedly appears to decrease with $R e$. Note, in the laminar flame, the soot sheet occupies a larger area (evident in a Media file), and thus, resulting in higher $D_{f}$. As Re increases, both - the soot concentration and filament size reduces, which leads to lower $D_{f}$.

Next, the fluctuation of soot field complexity in time is discussed by using the standard deviation of $D_{f}$ (marked in Fig. 11). For reference, the mean flame length (from Table 1) is also indicated in Fig. 11, except for $R e=21500$ case where flame-tip region was not imaged. The region between peak- $D_{f}$ (that coincides with the mean peak- $f_{v}$ region) and mean flame-tip is assumed to be the soot oxidation region. This assumption is made since the net reduction in $f_{v}$ is attributed to the dominance of soot oxidation over soot growth. $D_{f}$ fluctuates widely in the oxidation region, even in a laminar flame, likely due to the buoyancy effect. Additionally, significant values of $D_{f}$ are noted, even beyond the mean flame-tip. Since simultaneous $\mathrm{OH} / \mathrm{LII}$ data is unavailable, it remains unknown whether the soot structures in these regions have been partially oxidized (or leaked) through the reaction zone. The peak- $f_{v}$ regions exhibit highest mean $D_{f}$ values. These peak- $D_{f}$ regions generally exhibit low temporal fluctuations of soot structure complexity, as noted from a relatively low standard deviation in Fig. 11.

To examine the global relationship between $D_{f}$ and $R e$, peak- $D_{f}$ parameter is used. Figure 12 shows the peak- $D_{f}$ variation with $R e$. As indicated earlier, regions of mean peak- $D_{f}$ and peak- $f_{v}$ nearly coincide. Thus, peak- $D_{f}$ and $D_{f}$ evaluated in peak- $f_{v}$ regions are almost identical. In the $R e=2100-7200$ range, $D_{f}$ grows sharply, which reflects an increased complexity of soot fields. In the turbulent region $(R e=7200-21500), D_{f}$ remains nearly constant. This indicates that in a high $R e$ range though the soot concentration reduces with $R e$, overall soot sheet structure complexity remains largely unaffected. Such saturation of $D_{f}$ with turbulence has also been reported for premixed flamefronts $[54,58]$. For a laminar premixed flame surface, a typical value of mean $D_{f}$ is 2.1 , while it increases to $\sim 2.35$ for turbulent $\left(u^{\prime} / S_{L}=20\right)$ flames $[54,58]$. 
This $D_{f}$ range is higher than the present values (2.12 to 2.24 ) evaluated for soot-skeleton structures. Since in Refs. [54, 58], outline criteria is used we also compare soot-outline based peak- $D_{f}$ in our turbulent flame $(R e=21500)$, which measures 2.38, close to the $D_{f}$ obtained for a turbulent premixed flame surface $[54,58]$. Note that as observed in Sec. 3.2, the non-premixed flame surface (marked by $\mathrm{OH}$ ) is only weakly convoluted relative to the soot filament structures. Overall, the fractal approach appears to be very promising to quantify the soot structure topology in turbulent flames. Note, due to $D_{f}$ sensitivity to evaluation methods, for quantitative comparison of $D_{f}$ across different studies, a $D_{f}$ deduction procedure should be specified in detail.

\subsection{Soot sheet thickness}

Soot sheet shape analysis is further extended by deducing the local thickness of soot sheets $\left(\lambda_{S}\right)$. The soot sheet scales may influence total soot yield. Additionally, soot oxidation efficacy may depend on $\lambda_{S}$. Thus, the knowledge of soot sheet thickness (as a function of $R e$ ) could provide insights into the effect of turbulence on soot formation and oxidation. Such length scale analysis has been reported by a few studies $[1,16,60,61]$. Motivated by the above reasons, 8зо $\lambda_{S}$ analysis is pursued. However, identification of soot sheet boundary in turbulent flames is challenging owing to highly irregular shapes, merging of soot sheets, and branching of soot filaments. Such difficulties are well recognized in Refs. [16, 61]. Our data processing approach relies on the sequential protocol of image smoothing and binarization through the adaptive local threshold.

835 The binarization method is identical to the one implemented for fractal analysis (detailed in Sec. S12.1). The procedure to determine sheet thickness is described in Sec. S12.2. $\lambda_{S}$ is obtained by deducing the soot filament centerline and boundary. A distance transform [62] is applied to the binarized $f_{v}$ field to obtain the distance between a given pixel and the soot sheet boundary. Next, the soot filament centerline is located by the skeletonization of the binarized image. Subsequently, the thickness is calculated as twice the distance between the soot filament centerline and boundary. This simplified approach provides 
local thickness, $\lambda_{S}$, with reasonable robustness. Due to sensitivity to threshold and limitation of planar LII, the deduced $\lambda_{S}$ is only a relative estimate of the true thickness. To obtain true $\lambda_{S}$, three-dimensionality needs to be accounted for either through tomographic or dual-plane imaging. Nonetheless, the present projected $\lambda_{S}$ provides a useful estimate of the true thickness. Although the soot sheets in all the flames were analyzed, results for the laminar flame $(R e=2100)$ are not included since unusually large values of thickness and unclear trends owing to buoyancy-induced sheet merging (that results in soot clouds).

The local $f_{v}$ is also extracted at the soot filament centerline (on the skeleton) to investigate the correlation between $f_{v}$ and $\lambda_{S}$. The relation between areaaveraged $f_{v}$ and $\lambda_{S}$ is examined. The available sub-fields are divided axially into $15-20 \mathrm{~mm}$ high regions. The radial domain is maintained at $r=-44$ to $45 \mathrm{~mm}$. Instantaneous local $\lambda_{S}$ and $f_{v}$ values are averaged - first, within a given $15-20 \mathrm{~mm}$ high region (i.e., spatially) and then temporally over several frames $(1000-2000)$. The deduced average values of $f_{v}$ and $\lambda_{S}$ are plotted in Fig. 13 for different Re. These trends appear to follow the power fit, as also demonstrated by Mahmoud et al. [16]. The authors compared the correlation between sheet thickness and $f_{v}$; both averaged over a given soot sheet region. A global power fit function between sheet thickness and $f_{v}$ was found, independent of $R e$ [16]. However, the present observation in Fig. 13 indicates that the trend is global (power fit), but fit coefficients indeed depend on Re. Note, in [16], quantities $\left(f_{v}\right.$ and $\left.\lambda_{S}\right)$ are averaged over a single soot sheet rather than in a certain spatial region. It is unclear to what extent this difference in analysis protocol could affect the results and derived conclusions.

Note, the above semi-global analysis does not preserve local correlation. Therefore, we also analyze local correlations between $f_{v}$ and $\lambda_{S}$ by retaining pixel-to-pixel correspondence. Figure 14a shows the mean $f_{v}$ conditioned on s7o $\lambda_{S}$. To obtain this plot, the local $f_{v}$ and $\lambda_{S}$ pairs along the flame length are combined. Consequently, deduced analysis combinedly represents the behavior of soot inception, growth, and oxidation regions. Next, $f_{v}$ within a given $\lambda_{S}$ bins are averaged. In this manner, local correspondence between $f_{v}$ and $\lambda_{S}$ is 
preserved, despite performing the bin-averaging. The trends in Fig. 14a are drastically different from the semi-global analysis presented in Fig. 13. In Fig. 14a, for lower $\lambda_{S}, f_{v}$ increases with sheet thickness, similar to the semi-global trend noted in Fig. 13. However, $f_{v} \mid \lambda_{S}$ reaches a peak value at a certain sheet thickness. The $f_{v} \mid \lambda_{S}$ curve is not symmetric about the peak. The statistical analysis and peak $f_{v} \mid \lambda_{S}$ behavior is reported for the first time. Thus, a dedicated study is needed to explain the reasons for the occurrence of peak- $f_{v}$ at a preferred soot sheet thickness.

To examine the effect of $R e$ on $f_{v} \mid \lambda_{S}$, a peak (or mode) value is extracted from Fig. 14a. To detect the peak, data points are fitted with exponential pulses. Figure $14 \mathrm{~b}$ shows the variation of mode- $f_{v} \mid \lambda_{S}$ with $R e . f_{v}$ decreases 885 with $R e$ in an identical manner as of other representations in Figs. 8a and 9f. Thus, our characteristic choice of mode- $f_{v} \mid \lambda_{S}$ is representative of the physical phenomena. Soot sheet thickness at which $f_{v} \mid \lambda_{S}$ peaks (denoted by $\lambda_{S . m}$ ) is also plotted in Fig. 14b. Though trend appears to be linear with $R e$, there is uncertainty due to limited data points, imaging resolution, and the choice of the characteristic parameter $\left(\lambda_{S . m}\right)$.

In turbulent flames, the effect of $R e$ on $\lambda_{S}$ is not straightforward. In laminar one-dimensional flames, soot sheet thickness was observed to decrease with strain rate [51]. A similar observation can be noted from Lee et al. [1] in the soot inception regions of the turbulent jet flames where $\lambda_{S}$ decreased with $R e$.

895 However, in the soot growth and oxidation regions, $\lambda_{S}$ appears to increase with $R e$ (interpreted from data in [1]). In the present analysis, since the $f_{v^{-}} \lambda_{S}$ pairs along the entire flame height are combined, the soot inception, growth, and oxidation regions are not considered independently. The characteristic sheet thickness, $\lambda_{S . m}$ in Fig. $14 \mathrm{~b}$ is observed to increase with $R e$, similar to the data in [1] for soot growth and oxidation regions. Further analysis is needed to gain a deeper understanding of the effect of $R e$ on soot sheet thickness. The present analysis is a preliminary step towards understanding $f_{v}-\lambda_{S}$ relationship in turbulent flames. 


\section{Conclusions}

905 laser-based measurements. Reynolds number $(R e)$ was varied from 2100 to 21500, which covers laminar and turbulent regimes. Measured data include soot concentration $\left(f_{v}\right)$, soot-precursor $(\mathrm{PAH})$, reaction zone $(\mathrm{OH})$, and boundary conditions. The effect of Re on soot and other quantities is examined. Spatial and intensity correlations between soot and PAH are analyzed. Intermittency in soot, $\mathrm{PAH}$, and $\mathrm{OH}$ structures is also investigated. Finally, soot filament topology is studied using fractal dimension and soot-sheet thickness. The key findings of this work are summarized below.

In a soot inception region, species exist in the following radial order: fuel, appreciably with $R e$ and flame height, which suggests that the heat release rate is less affected by turbulence. In the turbulent flame (Re 21500), the thickness of the $\mathrm{OH}$ zone at the flame base is appreciably larger than low Re flames. This increase in $\mathrm{OH}-z o n e$ is likely associated with the edge flame which can form in lifted jet flames owing to partial premixing.

Soot and PAH concentrations decrease with Re. In a momentum-dominated range of $R e(5000-21500)$, both mean and most-probable $f_{v}$ values decrease in a near-exponential manner. A decrease in $f_{v}$ with $R e$ is mainly due to reduced (global and local) residence time and possibly due to increased scalar dissipation rate that in turn reduces $\mathrm{PAH}$ formation. In the $R e=2100-7200$ range, the rate of decrease in soot concentration with $\mathrm{PAH}$ is nearly constant. In a turbulent regime $(R e=7200-21500)$, the soot decrease rate with PAH is sharper, possibly due to reduced local residence time owing to turbulent eddies. PAH appears to diffuse in space, whereas soot fields are highly localized due to

PAH structures. Soot structures are highly intermittent. Soot intermittency is greatly influenced by $R e$, whereas PAH intermittency is mildly influenced while $\mathrm{OH}$ intermittency is the least affected by turbulence. 
The fractal analysis requires careful image processing to identify soot sheets. analyze soot structure topology.

Finally, the soot-sheet thickness is obtained by developing a robust image processing approach. Correlation between sheet thickness and $f_{v}$ is examined in semi-global and local manners. From a semi-global correlation, $f_{v}$ is observed 945 to increase with thickness monotonically in a power-law manner. Coefficients of power-fit are found to be dependent on $R e$. The local correlation of $f_{v}$ vs. sheet thickness indicated non-monotonic behavior, which to our knowledge, is reported for the first time. A dedicated study is needed to explore physical reasons for the non-monotonic trend.

Overall, this work examined various aspects of sooting jet flames through detailed analysis. Original contributions of this work are soot-PAH correlation, fractal analysis, and soot concentration/sheet thickness relationship. Additionally, soot measurements in a turbulent $n$-butane flame are performed for the first time. Physical insights and database derived from the present and companion paper (Part 2) [32] can aid in the validation of turbulence and soot chemistry models focused on practical fuels.

\section{Acknowledgments}

The project (ASMAPE) was funded by the French National Research Agency (ANR) under contract no. ANR-13-TDMO-0002. Dr. I.A. Mulla acknowledges support through Marie Skłodowska-Curie Individual Fellowship (ID: 747576) awarded by the European Commission under H2020-EU.1.3.2 scheme. The authors thank Dr. G. Godard and Mrs. C. Gobin for their assistance in laser 
installations. The assistance of Mr. B. Quevreux (and workshop group) in burner fabrication is gratefully acknowledged. 
Table 1: Flame conditions. Air flow rate is kept constant at $5(\mathrm{~g} / \mathrm{s})$.

\begin{tabular}{ccccccccc}
\hline Sr. & $R e$ & $h_{\text {lift }}$ & $\sigma_{h}$ & $L_{f}$ & $W_{f}$ & $\dot{m}_{f}$ & $U_{j}$ & $U_{j} / d$ \\
No. & $(-)$ & $(m m)$ & $(m m)$ & $(m m)$ & $(m m)$ & $(g / s)$ & $(m / s)$ & $(1 / s)$ \\
\hline 1 & 2100 & - & - & 405 & 17 & 0.03 & 2.7 & 1125 \\
2 & 5000 & - & - & 470 & 23 & 0.07 & 6.3 & 2625 \\
3 & 7200 & 11 & 0.6 & 545 & 27 & 0.10 & 9.0 & 3750 \\
4 & 21500 & 53 & 3.3 & 675 & 48 & 0.30 & 27.1 & 11300 \\
\hline
\end{tabular}




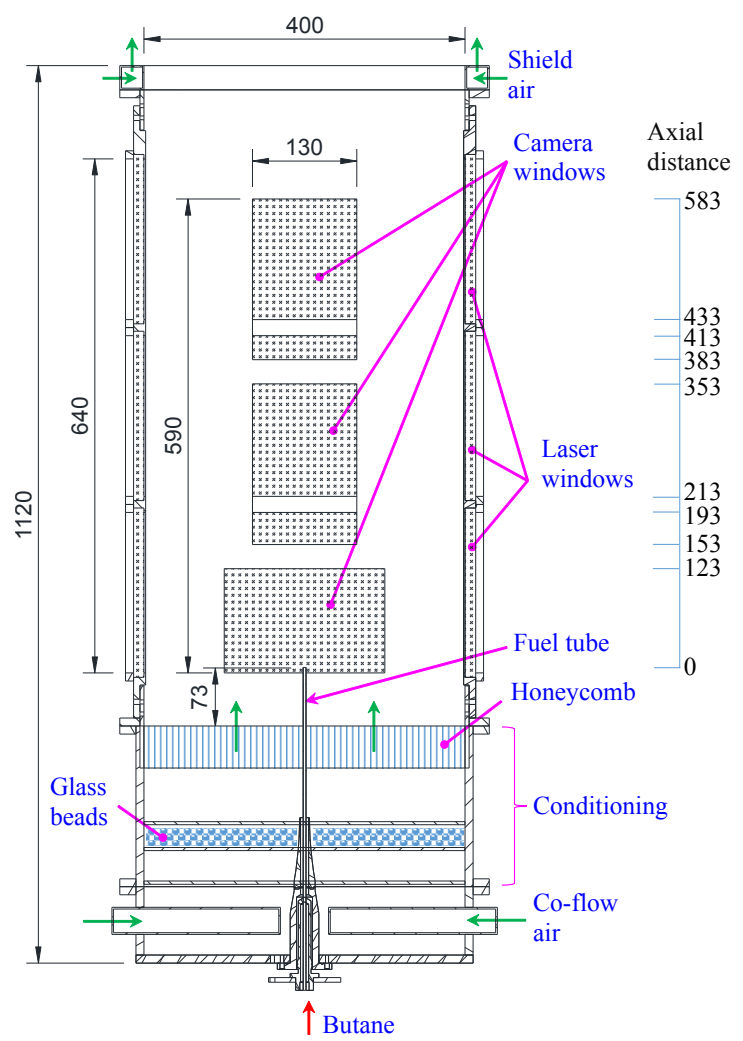

Figure 1: Burner geometry (dimensions are in $\mathrm{mm}$ ). Optically accessible regions are shaded and the corresponding dimensions are marked on the right. 
(a)

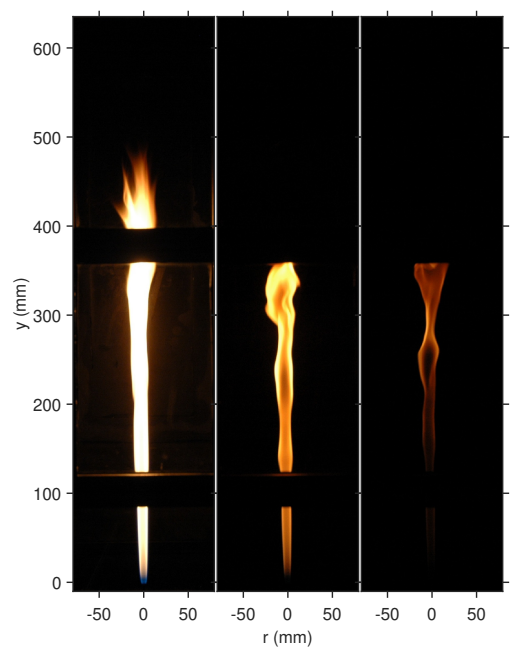

(c)

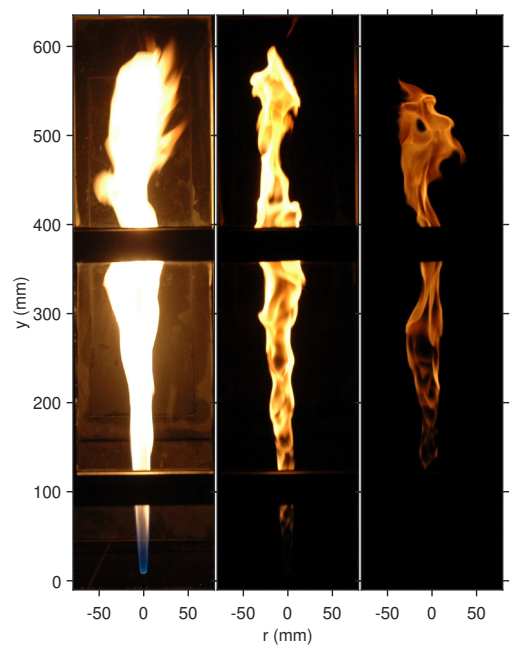

(b)

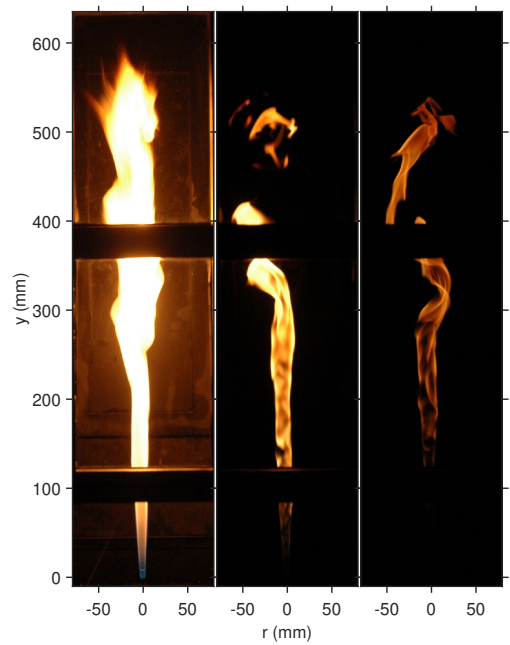

(d)

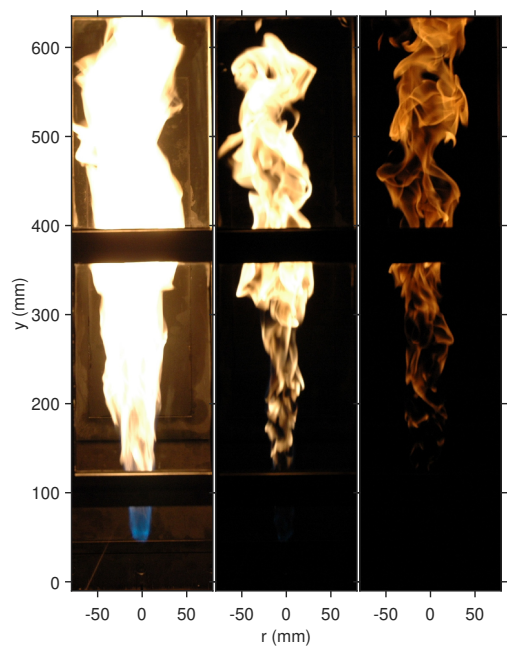

Figure 2: Flame photographs at different exposures, $1 / 20 \mathrm{~s}$ (left), 1/500 s (middle), and 1/8000 s (right): (a) Re 2100, (b) Re 5000, (c) Re 7200, and (d) Re 21500. 


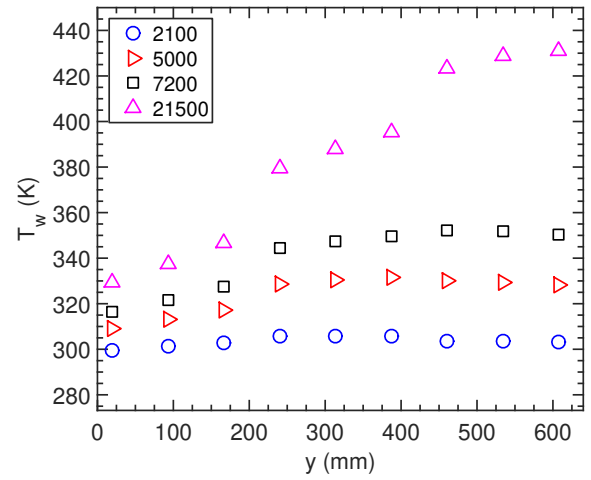

Figure 3: Wall temperature measured at different $R e$ as marked in the legend.

(a)

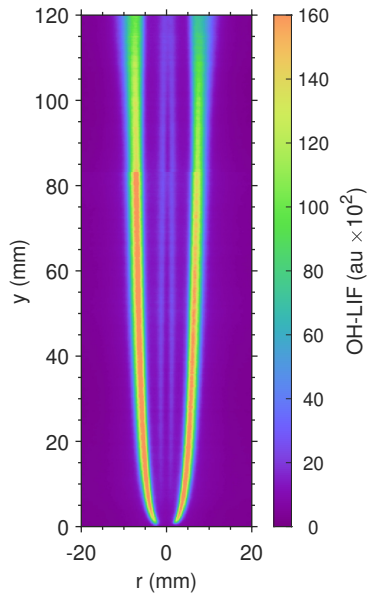

(b)

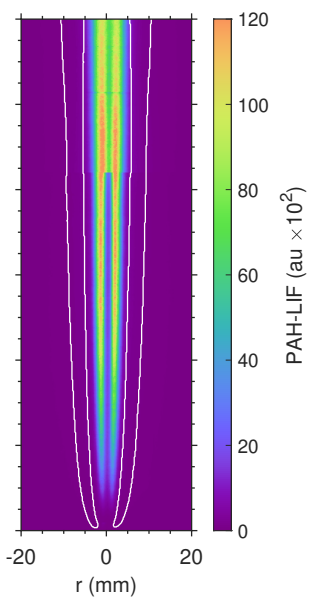

(c)

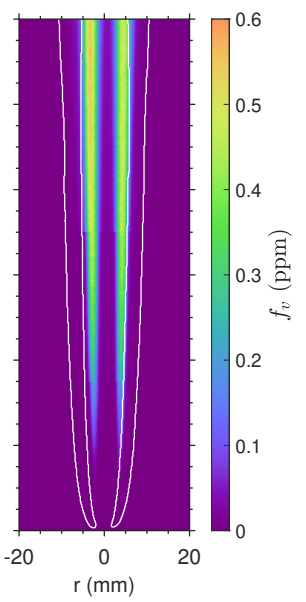

Figure 4: Mean fields at Re 2100: (a) OH-PLIF, (b) PAH-PLIF, (c) Soot volume fraction. White curve represents an $\mathrm{OH}$ iso-contour. 
(a)

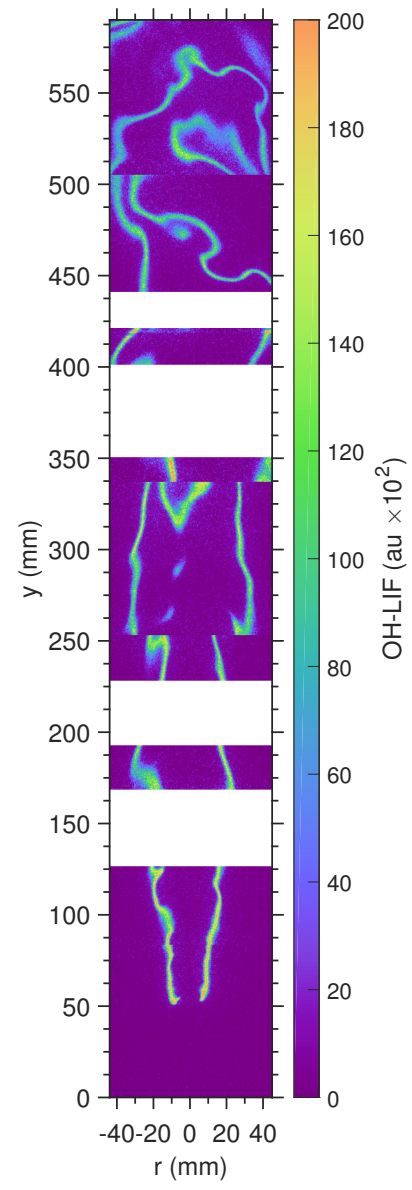

(b)

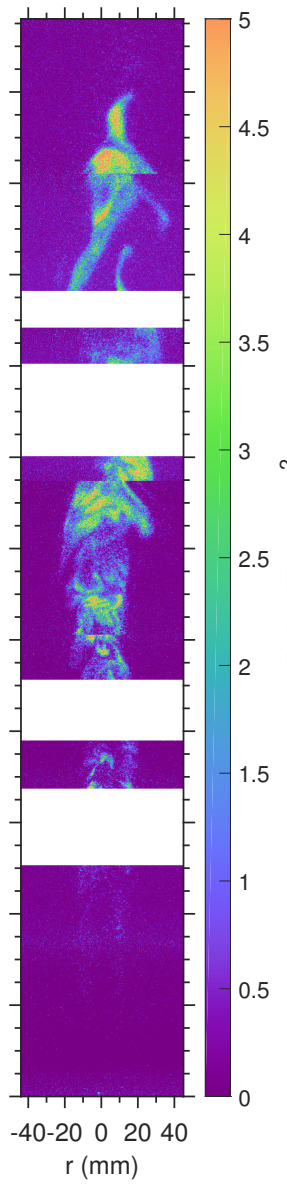

(c)

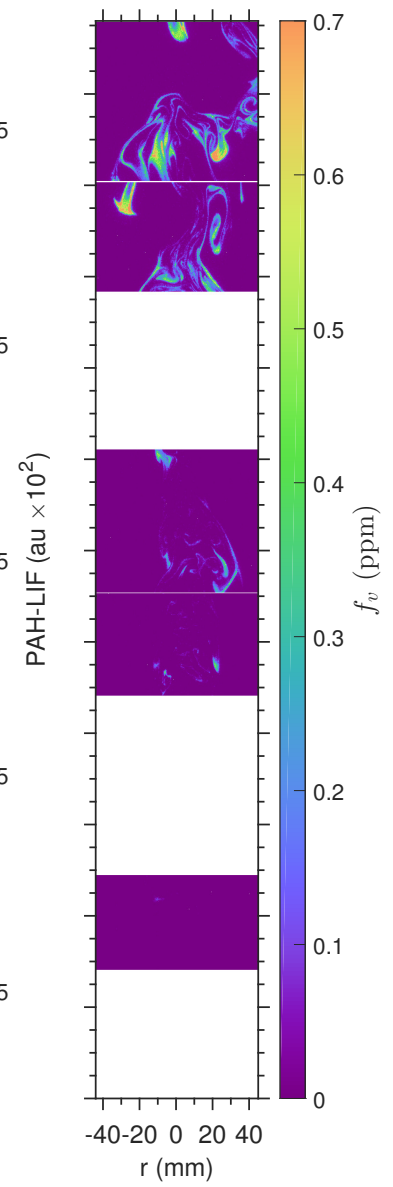

Figure 5: Instantaneous fields of: (a) OH-PLIF, (b) PAH-PLIF, and (c) Soot concentration, at Re 21500 . 
(a)

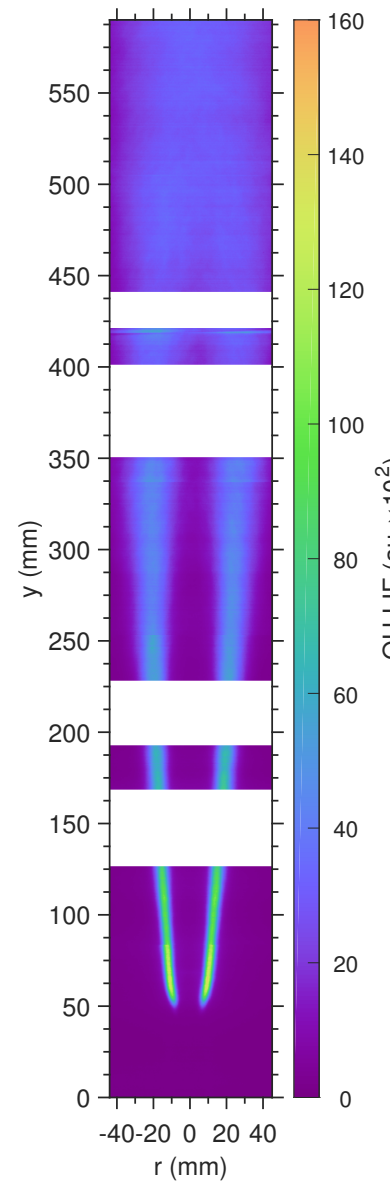

(b)

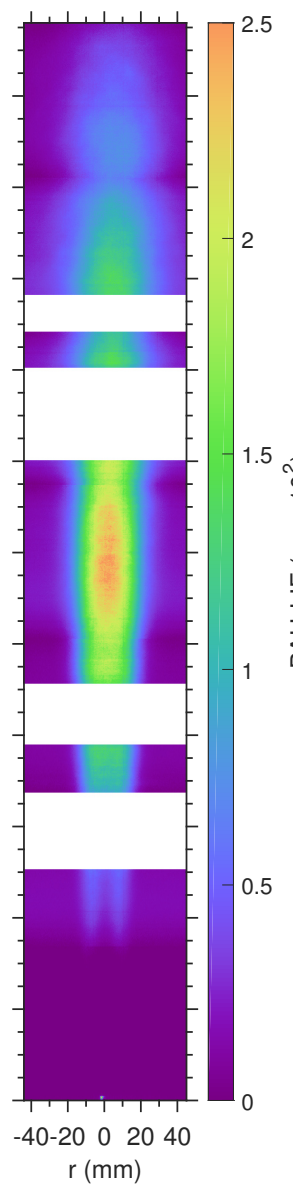

(c)

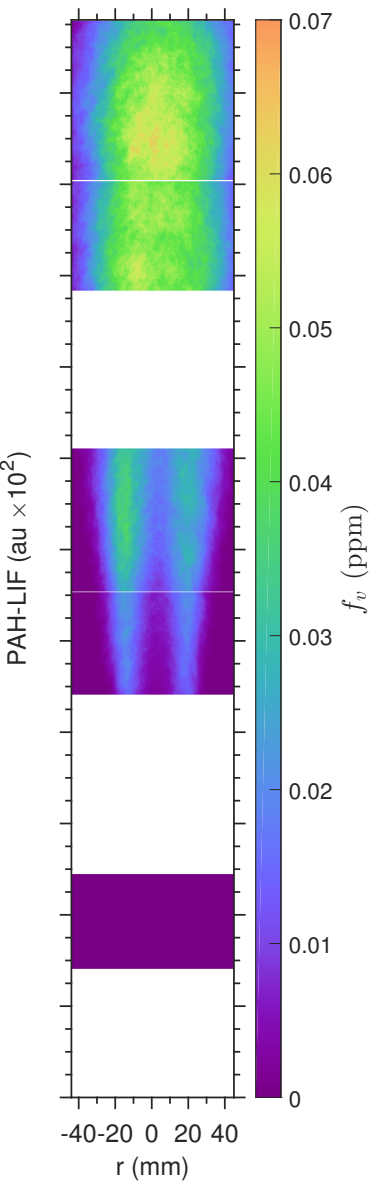

Figure 6: Mean fields of: (a) OH-PLIF, (b) PAH-PLIF, and (c) Soot concentration, at Re 21500 . 
(a)

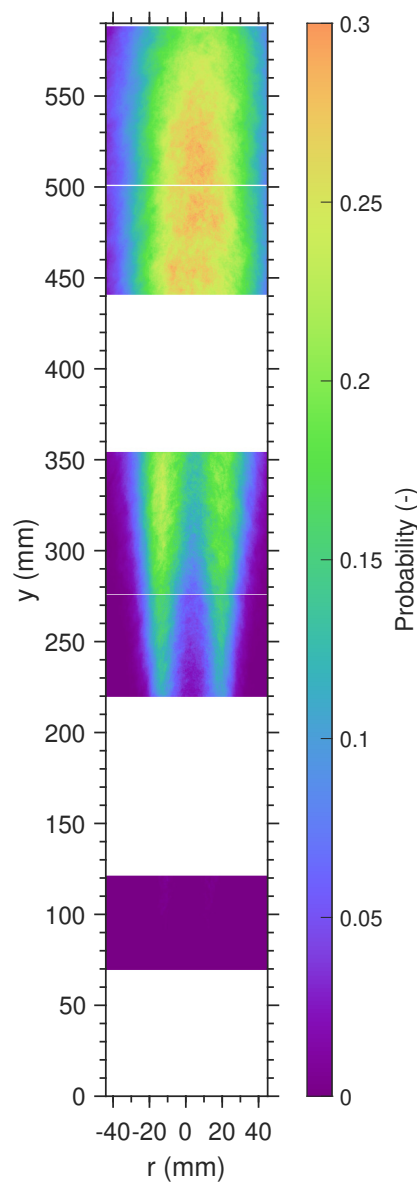

(b)

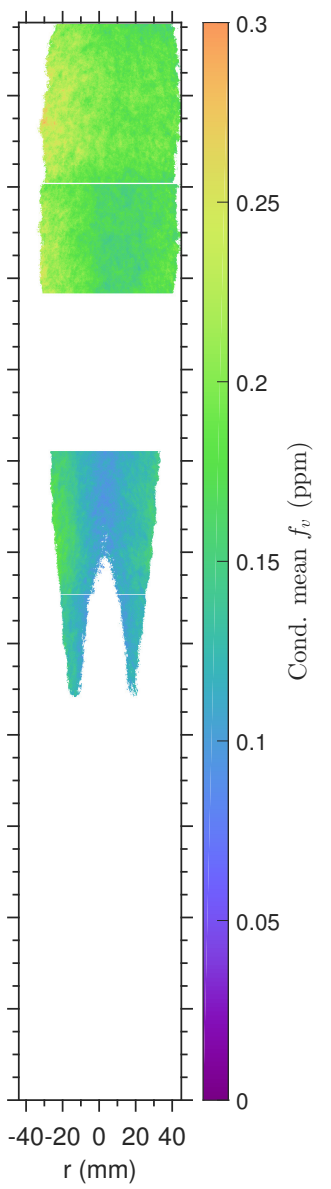

Figure 7: (a) Soot probability, (b) Conditionally averaged $f_{v}$, at $R e 21500$. 
(a)

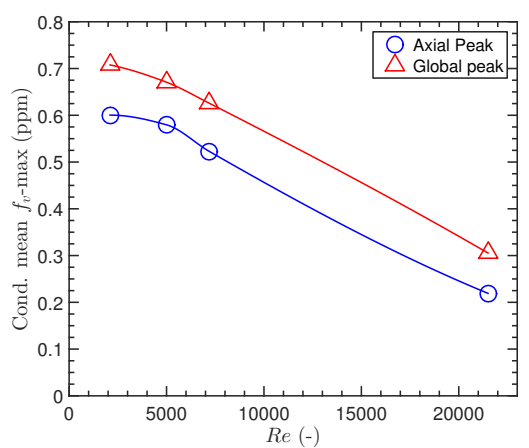

(c) (b)

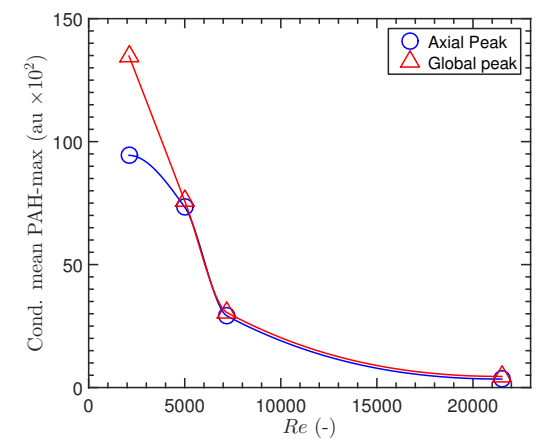

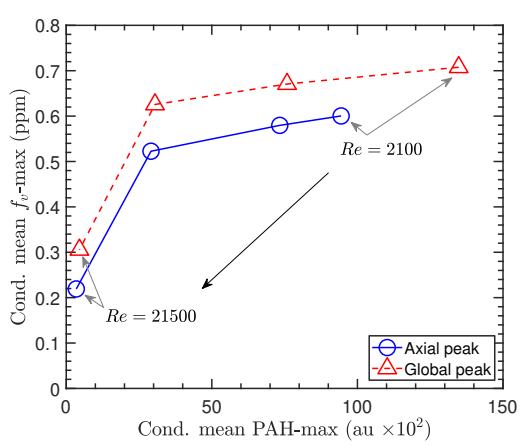

Figure 8: Axial and global peaks in: a) conditional mean $f_{v}$, b) conditional mean PAH, c) conditional peak- $f_{v}$ and PAH as a function of $R e$. 
(a)

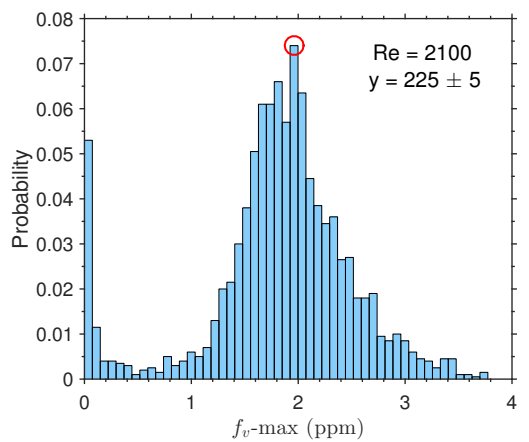

(c)

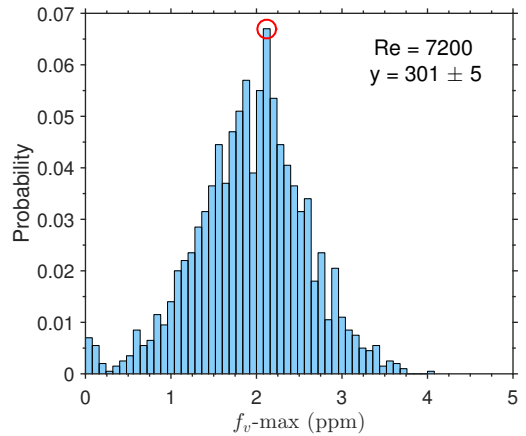

(e)

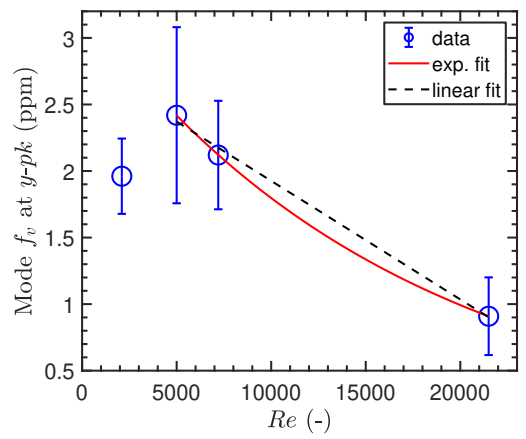

(b)

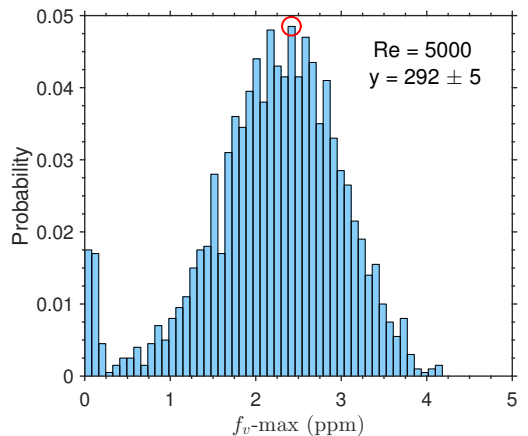

(d)

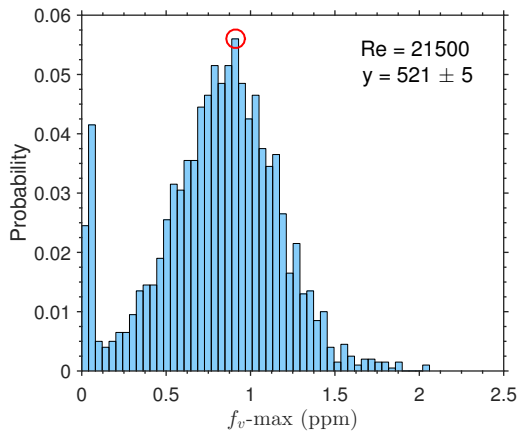

(f)

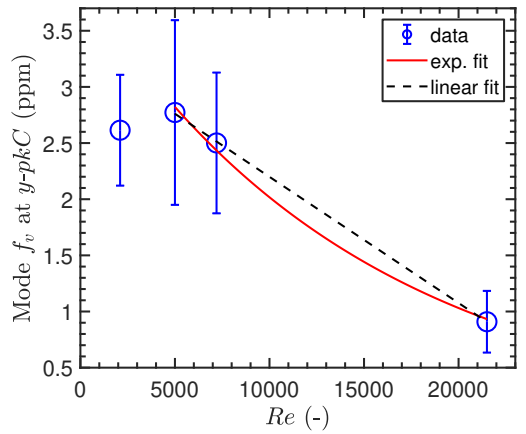

Figure 9: PDF of local peak- $f_{v}$ in the axial region where the unconditionally averaged centerline $f_{v}$ peaks $(y-p k):(a) R e 2100$, (b) $R e$ 5000, (c) $R e$ 7200, and (d) $R e 21500$, (e) mode- $f_{v}$, and (f) mode- $f_{v}$ in the axial region where the conditionally averaged centerline $f_{v}$ peaks $(y-p k C)$, corresponding PDFs are available in Fig. S23. 


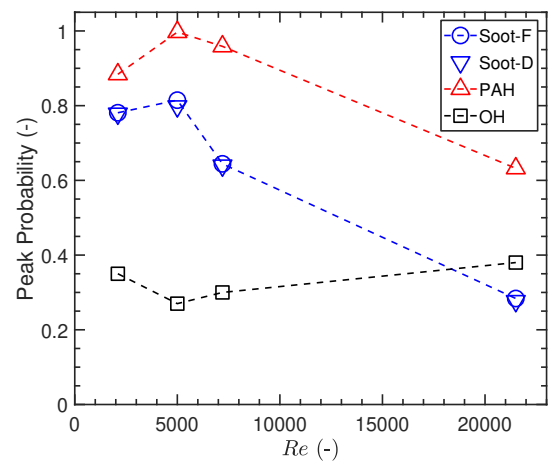

Figure 10: Peak probability of soot, $\mathrm{OH}, \mathrm{PAH}$ with $R e$. The letter "-F" and "-D" signify evaluation with fixed and dynamic thresholds, respectively.

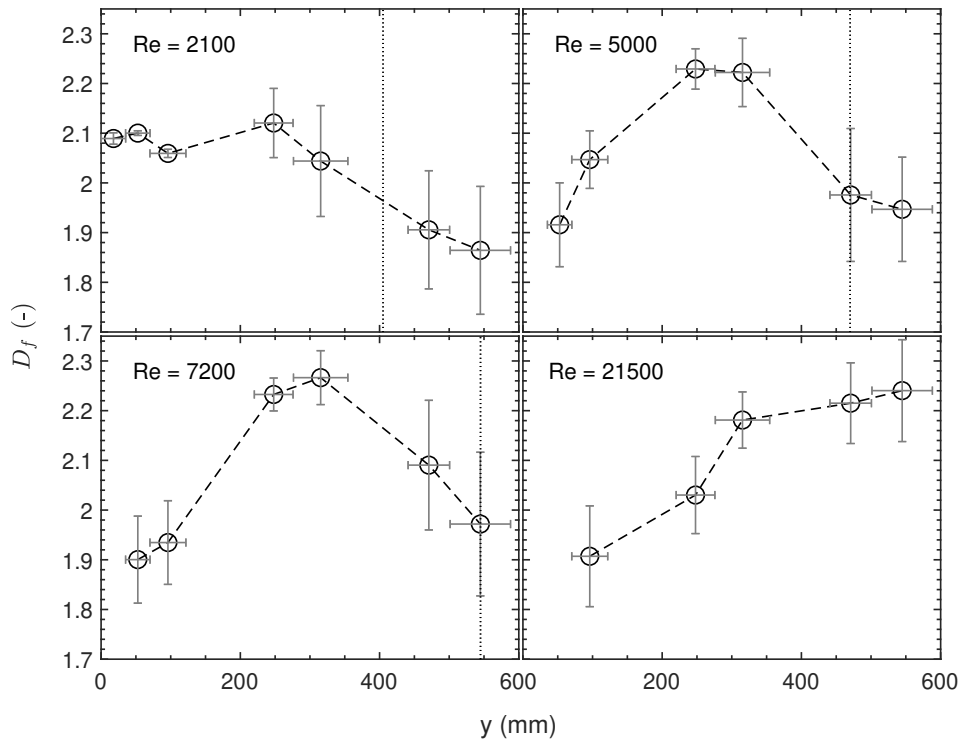

Figure 11: Evolution of mean characteristic fractal dimension along the flame length. Vertical bars indicate standard deviation as $\pm \sigma$, while horizontal bars mark the $y$ range over which $D_{f}$ is evaluated. The vertical dotted line marks the mean flame length. 


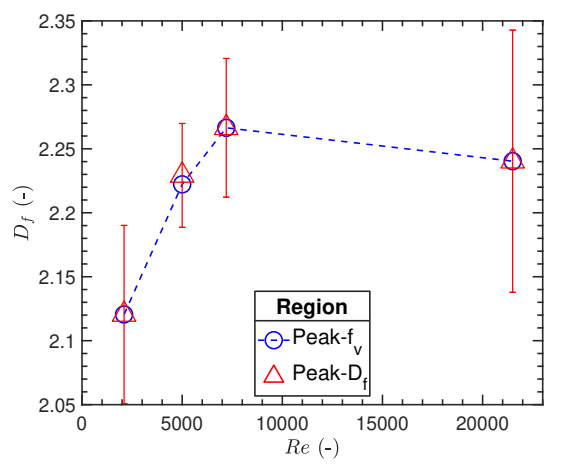

Figure 12: Variation of peak characteristic fractal dimension with Re. Error bars indicate standard deviation as $\pm \sigma$.

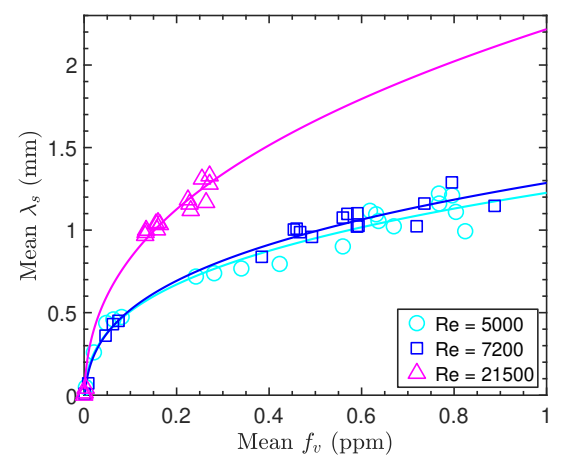

Figure 13: Area- and time-averaged $f_{v}$ variation with soot sheet thickness.

(a)

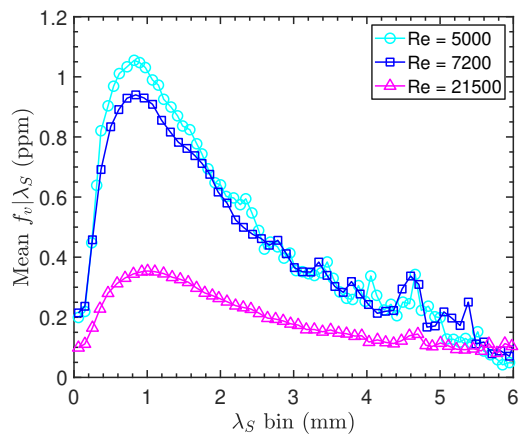

(b)

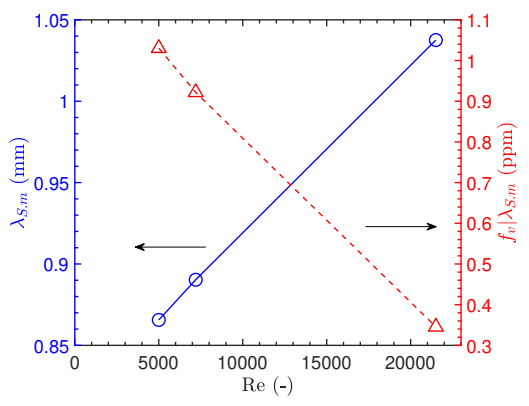

Figure 14: Soot concentration and sheet thickness correlation: a) $f_{v}$ conditioned on sheet thickness, b) mode- $f_{v}$ conditioned on $\lambda_{S}$ and corresponding $\lambda_{S}$. 


\section{References}

[1] S.-Y. Lee, S. R. Turns, R. J. Santoro, Measurements of soot, OH, and $\mathrm{PAH}$ concentrations in turbulent ethylene/air jet flames, Combust. Flame 156 (12) (2009) 2264-2275. doi:10.1016/j . combustflame.2009.09.005.

[2] N. Qamar, Z. Alwahabi, Q. Chan, G. Nathan, D. Roekaerts, K. King, Soot volume fraction in a piloted turbulent jet non-premixed flame of natural gas, Combust. Flame 156 (7) (2009) 1339-1347. doi:10.1016/j. combustflame.2009.02.011.

[3] C. R. Shaddix, J. Zhang, R. W. Schefer, J. Doom, J. C. Oefelein, S. Kook, L. M. Pickett, H. Wang, Understanding and predicting soot generation in turbulent non-premixed jet flames, Sand2010-7178, Sandia Report.

[4] P. Rodrigues, B. Franzelli, R. Vicquelin, O. Gicquel, N. Darabiha, Coupling an LES approach and a soot sectional model for the study of sooting turbulent non-premixed flames, Combust. Flame 190 (2018) 477-499. doi:10.1016/j.combustflame.2017.12.009.

[5] M. Köhler, K. P. Geigle, W. Meier, B. M. Crosland, K. A. Thomson, G. J. Smallwood, Sooting turbulent jet flame: characterization and quantitative soot measurements, Appl. Phys. B 104 (2) (2011) 409-425. doi: $10.1007 / \mathrm{s} 00340-011-4373-\mathrm{y}$.

[6] M. Köhler, K.-P. Geigle, T. Blacha, P. Gerlinger, W. Meier, Experimental characterization and numerical simulation of a sooting lifted turbulent jet diffusion flame, Combust. Flame 159 (8) (2012) 2620-2635. doi:10.1016/ j.combustflame.2012.01.015.

[7] D. Gu, Z. Sun, B. B. Dally, P. R. Medwell, Z. T. Alwahabi, G. J. Nathan, Simultaneous measurements of gas temperature, soot volume fraction and primary particle diameter in a sooting lifted turbulent ethylene/air non-premixed flame, Combust. Flame 179 (2017) 33-50. doi: $10.1016 / j$. combustflame.2017.01.017. 
[8] S. Kruse, J. Ye, Z. Sun, A. Attili, B. Dally, P. Medwell, H. Pitsch, Experimental investigation of soot evolution in a turbulent non-premixed

[14] S. Mahmoud, G. Nathan, Z. Alwahabi, Z. Sun, P. Medwell, B. Dally, The effect of exit strain rate on soot volume fraction in turbulent non-premixed jet flames, Proc. Combust. Inst. 36 (1) (2017) 889-897. doi:10.1016/j . proci.2016.08.055. 
[20] K. P. Geigle, R. Hadef, M. Stöhr, W. Meier, Flow field characterization of pressurized sooting swirl flames and relation to soot distributions, Proc. Combust. Inst. 36 (3) (2017) 3917-3924. doi:10.1016/j .proci.2016.09. 024. Time-resolved study of transient soot formation in an aero-engine model combustor at elevated pressure, Proc. Combust. Inst. 37 (4) (2019) 54215428. doi:10.1016/j.proci.2018.05.122. 
[22] S. Chatterjee, Ömer L. Gülder, Soot concentration and primary particle size in swirl-stabilized non-premixed turbulent flames of ethylene and air, Exp. Therm. Fluid Sci. 95 (2018) 73-80. doi:10.1016/j.expthermflusci. 2018.01 .035$.

[23] M. Roussillo, P. Scouflaire, S. Candel, B. Franzelli, Experimental investigation of soot production in a confined swirled flame operating under perfectly premixed rich conditions, Proc. Combust. Inst. 37 (1) (2019) 893-901. doi:10.1016/j.proci.2018.06.110.

[24] M. Grader, C. Eberle, P. Gerlinger, Large-eddy simulation and analysis of a sooting lifted turbulent jet flame, Combust. Flame 215 (2020) 458-470. doi:10.1016/j.combustflame.2020.01.042.

[25] H. Yamashita, M. Shimada, T. Takeno, A numerical study on flame stability at the transition point of jet diffusion flames, Symp. (Int.) Combust. 26 (1) (1996) 27-34. doi:10.1016/s0082-0784(96)80196-2.

[26] J. Kent, S. Bastin, Parametric effects on sooting in turbulent acetylene diffusion flames, Combust. Flame 56 (1) (1984) 29-42. doi:10.1016/ 0010-2180 (84) 90003-8.

[27] International sooting flame (ISF) workshop, https://www . adelaide.edu . $\mathrm{au} / \mathrm{cet} /$ isf workshop/data-sets/turbulent/ (Accessed on 2021-06-29).

[28] D. Bartos, M. Dunn, M. Sirignano, A. D'Anna, A. R. Masri, Tracking the evolution of soot particles and precursors in turbulent flames using laserinduced emission, Proc. Combust. Inst. 36 (2) (2017) 1869-1876. doi: 10.1016/j.proci.2016.07.092.

[29] Y. Huang, C. Sung, J. Eng, Dilution limits of n-butane/air mixtures under conditions relevant to HCCI combustion, Combust. Flame 136 (4) (2004) 457-466. doi:10.1016/j. combustflame.2003 .10.011.

1075

[30] N. M. Marinov, W. J. Pitz, C. K. Westbrook, A. M. Vincitore, M. J. Castaldi, S. M. Senkan, C. F. Melius, Aromatic and polycyclic aromatic 
hydrocarbon formation in a laminar premixed n-butane flame, Combust. Flame 114 (1-2) (1998) 192-213. doi:10.1016/s0010-2180(97)00275-7.

[31] W. J. Pitz, C. K. Westbrook, Chemical kinetics of the high pressure oxidation of n-butane and its relation to engine knock, Combust. Flame 63 (1-2) (1986) 113-133. doi:10.1016/0010-2180 (86)90115-x.

[32] I. Mulla, J. Yon, D. Honoré, C. Lacour, B. Lecordier, A. Cessou, Comprehensive characterization of sooting butane jet flames, Part 2: temperature and soot particle size, Combust. Flame CNF-D-18-00807R2 (2021) Accepted.

[33] C. Schulz, B. Kock, M. Hofmann, H. Michelsen, S. Will, B. Bougie, R. Suntz, G. Smallwood, Laser-induced incandescence: recent trends and current questions, Appl. Phys. B 83 (3) (2006) 333-354. doi:10.1007/ s00340-006-2260-8.

[34] C. S. Moreau, E. Therssen, X. Mercier, J. Pauwels, P. Desgroux, Two-color laser-induced incandescence and cavity ring-down spectroscopy for sensitive and quantitative imaging of soot and PAHs in flames, Appl. Phys. B 78 (34) (2004) 485-492. doi:10.1007/s00340-003-1370-9.

[35] S. Bejaoui, X. Mercier, P. Desgroux, E. Therssen, Laser induced fluorescence spectroscopy of aromatic species produced in atmospheric sooting flames using UV and visible excitation wavelengths, Combust. Flame 161 (10) (2014) 2479-2491. doi:10.1016/j.combustflame.2014.03.014.

[36] A. Cessou, D. Stepowski, Planar laser induced fluorescence measurement of $[\mathrm{OH}]$ in the stabilization stage of a spray jet flame, Combust. Sci. Technol. 118 (4-6) (1996) 361-381. doi:10.1080/00102209608951986.

[37] J. Luque, D. Crosley, LIFBASE: Database and spectral simulation program (version 2.1.1), Tech. Rep. MP 99-009, SRI International (1999).

[38] N.-E. Olofsson, H. Bladh, A. Bohlin, J. Johnsson, P.-E. Bengtsson, Are sooting premixed porous-plug burner flames one-dimensional? A laser- 

293-309. doi:10.1080/00102202.2012.718006.

[39] M. Köhler, I. Boxx, K. Geigle, W. Meier, Simultaneous planar measurements of soot structure and velocity fields in a turbulent lifted jet flame at 3 kHz, Appl. Phys. B 103 (2) (2011) 271. doi:10.1007/s00340-011-4549-5.

[40] T. Mouton, X. Mercier, P. Desgroux, Isomer discrimination of PAHs formed in sooting flames by jet-cooled laser-induced fluorescence: application to the measurement of pyrene and fluoranthene, Appl. Phys. B 122 (5) (2016) 123. doi:10.1007/s00340-016-6397-9.

[41] P. Desgroux, X. Mercier, K. A. Thomson, Study of the formation of soot and its precursors in flames using optical diagnostics, Proc. Combust. Inst. 34 (1) (2013) 1713-1738. doi:10.1016/j.proci.2012.09.004.

[42] B. Hu, B. Yang, U. O. Koylu, Soot measurements at the axis of an ethylene/air non-premixed turbulent jet flame, Combust. Flame 134 (1-2) (2003) 93-106. doi:10.1016/s0010-2180 (03) 00085-3.

[43] M. Frenklach, H. Wang, Detailed modeling of soot particle nucleation and growth, Symp. (Int.) Combust. 23 (1) (1991) 1559-1566. doi:10.1016/ s0082-0784 (06) 80426-1.

[44] H. Guo, P. M. Anderson, P. B. Sunderland, Optimized rate expressions for soot oxidation by $\mathrm{OH}$ and O2, Fuel 172 (2016) 248-252. doi:10.1016/j . fuel.2016.01.030.

[45] K. M. Lyons, Toward an understanding of the stabilization mechanisms of lifted turbulent jet flames: Experiments, Prog. Energy Combust. Sci. 33 (2) (2007) 211-231. doi:10.1016/j.pecs. 2006.11.001.

[46] A. Upatnieks, J. F. Driscoll, C. C. Rasmussen, S. L. Ceccio, Liftoff of 1130 turbulent jet flames - assessment of edge flame and other concepts using cinema-PIV, Combust. Flame 138 (3) (2004) 259-272. doi:10.1016/j . combustflame.2004.04.011. 
[47] F. Bisetti, G. Blanquart, M. E. Mueller, H. Pitsch, On the formation and early evolution of soot in turbulent nonpremixed flames, Combust. Flame 159 (1) (2012) 317-335. doi:10.1016/j.combustflame.2011.05.021.

[48] J. Appel, H. Bockhorn, M. Frenklach, Kinetic modeling of soot formation with detailed chemistry and physics: laminar premixed flames of c2 hydrocarbons, Combust. Flame 121 (1-2) (2000) 122-136. doi:10.1016/ s0010-2180 (99) 00135-2.

[49] A. Attili, F. Bisetti, M. E. Mueller, H. Pitsch, Formation, growth, and transport of soot in a three-dimensional turbulent non-premixed jet flame, Combust. Flame 161 (7) (2014) 1849-1865. doi:10.1016/j. combustflame.2014.01.008.

[50] A. Beltrame, P. Porshnev, W. Merchan-Merchan, A. Saveliev, A. Fridman, ${ }_{1145}$ L. Kennedy, O. Petrova, S. Zhdanok, F. Amouri, O. Charon, Soot and NO formation in methane-oxygen enriched diffusion flames, Combust. Flame 124 (1-2) (2001) 295-310. doi:10.1016/s0010-2180(00)00185-1.

[51] M. E. Decroix, W. L. Roberts, Transient flow field effects on soot volume fraction in diffusion flames, Combust. Sci. Technol. 160 (1) (2000) 165-189. doi:10.1080/00102200008935801.

[52] M. Stöhr, K. Geigle, R. Hadef, I. Boxx, C. Carter, M. Grader, P. Gerlinger, Time-resolved study of transient soot formation in an aero-engine model combustor at elevated pressure, Proc. Combust. Inst. 37 (4) (2019) 54215428. doi:10.1016/j.proci.2018.05.122.

[53] K. R. Sreenivasan, C. Meneveau, The fractal facets of turbulence, J. Fluid Mech. 173 (1986) 357-386. doi:10.1017/s0022112086001209.

[54] G. L. North, D. A. Santavicca, The fractal nature of premixed turbulent flames, Combust. Sci. Technol. 72 (4-6) (1990) 215-232. doi:10.1080/ 00102209008951648. 
[58] J. Mantzaras, P. Felton, F. Bracco, Fractals and turbulent premixed engine flames, Combust. Flame 77 (3-4) (1989) 295-310. doi:10.1016/ 0010-2180 (89) 90136-3.

[59] G. Gonzato, F. Mulargia, M. Ciccotti, Measuring the fractal dimensions of ideal and actual objects: implications for application in geology and geophysics, Geophys. J. Int. 142 (1) (2000) 108-116. doi:10.1046/j. $1365-246 x .2000 .00133 . x$.

[60] N. H. Qamar, G. J. Nathan, Z. T. Alwahabi, Q. N. Chan, Soot sheet dimensions in turbulent nonpremixed flames, Combust. Flame 158 (12) (2011) 2458-2464. doi:10.1016/j.combustflame.2011.04.017.

[61] Q. N. Chan, P. R. Medwell, G. J. Nathan, Algorithm for soot sheet quantification in a piloted turbulent jet non-premixed natural gas flame, Exp. Fluids 55 (10) (2014) 1827. doi:10.1007/s00348-014-1827-0.

[62] C. Maurer, R. Qi, V. Raghavan, A linear time algorithm for computing 1185 exact euclidean distance transforms of binary images in arbitrary dimensions, IEEE Trans. Pattern Anal. Mach. Intell. 25 (2) (2003) 265-270. doi:10.1109/tpami.2003.1177156. 